\title{
Primary Biliary Cirrhosis and Primary Sclerosing Cholangitis: a Review Featuring a Women's Health Perspective
}

\author{
Renée M. Marchioni Beery*1 ${ }^{1}$, Haleh Vaziri ${ }^{1}$ and Faripour Forouhar ${ }^{2}$ \\ ${ }^{1}$ Division of Internal Medicine, Department of Gastroenterology and Hepatology, University of Connecticut Health Center, \\ Farmington, CT, USA; ${ }^{2}$ Department of Pathology and Lab Medicine, University of Connecticut Health Center, Farmington, CT, USA
}

\begin{abstract}
Primary biliary cirrhosis (PBC) and primary sclerosing cholangitis (PSC) are two major types of chronic cholestatic liver disease. Each disorder has distinguishing features and variable progression, but both may ultimately result in cirrhosis and hepatic failure. The following offers a review of PBC and PSC, beginning with a general overview of disease etiology, pathogenesis, diagnosis, clinical features, natural course, and treatment. In addition to commonly associated manifestations of fatigue, pruritus, and fat-soluble vitamin deficiency, select disease-related topics pertaining to women's health are discussed including metabolic bone disease, hyperlipidemia and cardiovascular risk, and pregnancy-related issues influencing maternal disease course and birth outcomes. This comprehensive review of PBC and PSC highlights some unique clinical considerations in the care of female patients with cholestatic liver disease.

(C) 2014 The Second Affiliated Hospital of Chongqing Medical University. Published by XIA \& HE Publishing Ltd. All rights reserved.
\end{abstract}

\section{Introduction}

Primary biliary cirrhosis (PBC) and primary sclerosing cholangitis (PSC) are two major types of chronic cholestatic liver

Keywords: Primary biliary cirrhosis; Primary sclerosing cholangitis; Cholestasis; Women's health; Metabolic bone disease; Hyperlipidemia; Pregnancy; Fatigue; Pruritus; Fat-soluble vitamin deficiency.

Abbreviations: $\mathrm{AIH}$, autoimmune hepatitis; AIP, autoimmune pancreatitis; $A L P$, alkaline phosphatase; ALT, alanine aminotransferase; AMAs, antimitochondrial antibodies; ANA, antinuclear antibody; ASMA, anti-smooth muscle antibody; AST, aspartate aminotransferase; $B M D$, bone mineral density; $C A$, carbohydrate antigen; CCA, cholangiocarcinoma; $\mathrm{CI}$, confidence interval; DEXA, dual-energy $\mathrm{X}$-ray absorptiometry; ERCP, endoscopic retrograde cholangiopancreatography; FISH, fluorescence in situ hybridization; GGT, $\gamma$-glutamyltranspeptidase; HDL, high-density lipoprotein; HLAs, human leukocyte antigens; HMG-CoA, hydroxymethylglutaryl coenzyme A; HRT, hormone replacement therapy; IBD, inflammatory bowel disease; ICP, intrahepatic cholestasis of pregnancy; Ig, immunoglobulin; LCA, lithocholic acid; LDL, low-density lipoprotein; LT, liver transplantation; LP, lipoprotein; MBD, metabolic bone disease; MRI, magnetic resonance imaging; $\mathrm{MRCP}$, magnetic resonance cholangiopancreatography; $\mathrm{p}$ ANCA, perinuclear antineutrophil cytoplasmic antibodies; PBC, primary biliary cirrhosis; PSC, primary sclerosing cholangitis; RR, relative risk; TC, total cholesterol; Th, T-helper; UC, ulcerative colitis; UDCA, ursodeoxycholic acid; US FDA, US Food and Drug Administration; VLDLs, very-low-density lipoproteins. Received: 02 August 2014; Revised: 15 October 2014; Accepted: 19 October 2014 DOI: $10.14218 / \mathrm{JCTH} .2014 .00024$.

* Correspondence to: Renée M. Marchioni Beery, DO, Division of Internal Medicine, Department of Gastroenterology and Hepatology, 263 Farmington Avenue, Farmington, CT 06030-1845, USA. Tel: +01-860-679-3158, Fax: +01860-679-3159, E-mail: marchioni@uchc.edu disease. Both are slowly progressive disorders, coursing over 10-20 years from early to end-stage liver disease. ${ }^{1}$ The incidence and prevalence of these conditions appear to be rising. ${ }^{2}$ Cholestasis results from impaired bile formation and/or flow and may manifest clinically as fatigue, pruritus, and jaundice. Early biochemical markers of cholestasis include elevated levels of serum alkaline phosphatase (ALP) and $\gamma$-glutamyltranspeptidase (GGT) with conjugated hyperbilirubinemia in more advanced stages. Chronic cholestasis is generally defined by persistent abnormalities lasting $>6$ months.

The purpose of this work is to provide an overview of PBC and PSC as cholestatic liver disorders, with a focused, clinically-oriented review of commonly associated manifestations (fatigue, pruritus, and fat-soluble vitamin deficiency). This is followed by a description of disease-related clinical consequences as they relate to women's health. Knowledge of gender-specific issues in chronic liver disease is of particular relevance in the setting of $\mathrm{PBC}$, as it is a femalepredominant entity. Furthermore, heightened awareness and improved diagnostic testing have resulted in disease detection in younger women, including those with childbearing potential. Important women's health issues that will be addressed in this review include metabolic bone disease (MBD), hyperlipidemia and cardiovascular disease risk, and the influence of pregnancy on maternal disease and birth outcomes.

\section{Primary biliary cirrhosis}

PBC is a complex, chronic, and slowly progressive autoimmune liver disease that predominantly affects women. It is thought to be triggered by environmental factors in genetically susceptible individuals ${ }^{2}$ and is characterized by cholestatic liver biochemistries, the presence of antimitochondrial antibodies (AMAs), and predominantly T-lymphocytemediated destruction of small intrahepatic bile ducts. Portal inflammation with varying degrees of fibrosis can be seen histologically (Fig. 1-2). ${ }^{3}$ Progressive bile duct deterioration results in impaired secretion and hepatic retention of bile acid toxins. Pathophysiologic changes in PBC occur at different rates with variable degrees of severity and may ultimately lead to cirrhosis and hepatic failure without liver transplantation (LT). ${ }^{4}$

AMA, a characteristic and highly disease-specific autoantibody directed against the E2 subunit of the pyruvate dehydrogenase complex, is present in approximately $90-95 \%$ of affected PBC patients and $<1 \%$ of normal controls. ${ }^{3}$ Approximately $5-10 \%$ of patients with PBC are AMA negative. ${ }^{1}$ 


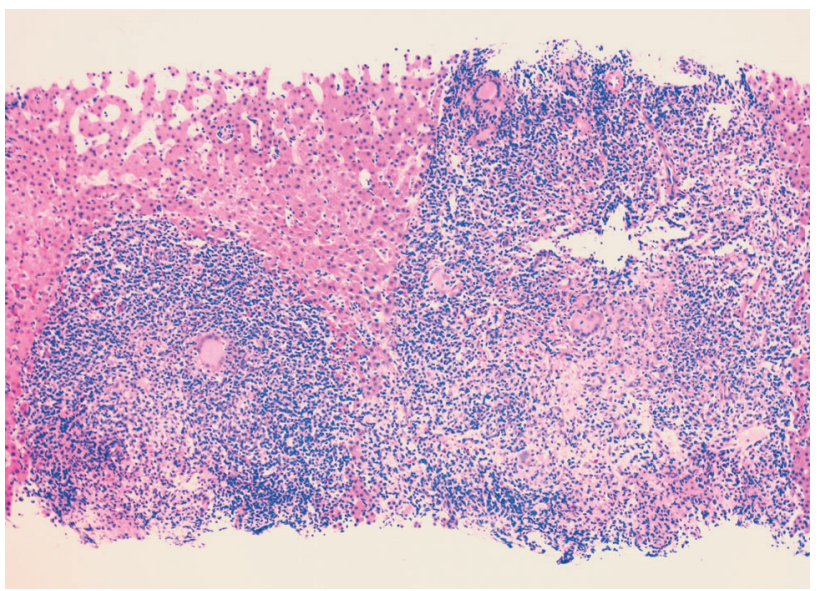

Fig. 1. H\&E, X100; Liver biopsy. The classic appearance of primary biliary cirrhosis in its early portal inflammatory stage demonstrating granulomatous features with interface hepatitis. The inflammatory infiltrate is typically composed of lymphocytes and plasma cells. The lymphocytes may form lymphoid nodules, occasionally with germinal centers. Inflammation typically surrounds the interlobular bile ducts that might show evidence of injury. Abbreviation: H\&E (Hematoxylin \& Eosin).

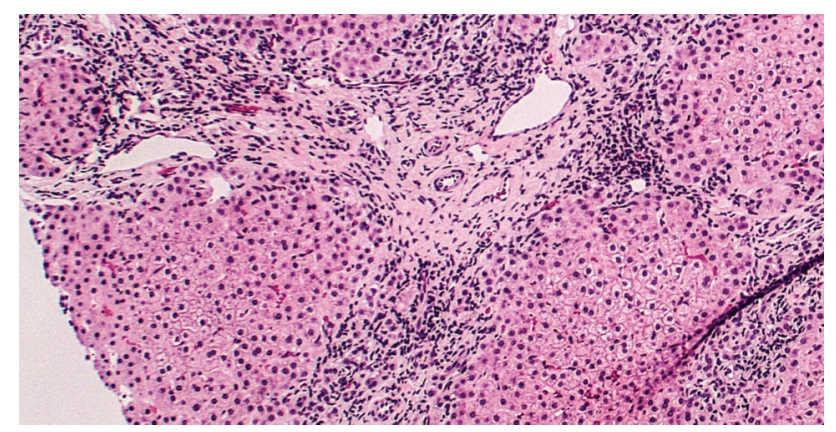

Fig. 2. H\&E, X200; Liver biopsy. An absence/paucity of bile ducts is seen with focal chronic inflammation in a portal area consistent with late-stage primary biliary cirrhosis.

Most patients have an elevated serum immunoglobulin (Ig) M, although this is neither highly sensitive nor specific. Total gamma globulin concentrations tend to remain normal and drop with the development of cirrhosis.

\section{Epidemiology and risk factors}

PBC has a female:male ratio of $10: 1$ and is most often diagnosed in middle-aged to elderly Caucasian females. ${ }^{2,5}$ Disease incidence and prevalence vary widely and have been reported to range from 0.33 to 5.8 per 100,000 inhabitants/year and from 1.9 to 40.2 per 100,000 inhabitants, respectively. ${ }^{2}$ The risk of PBC is increased in those with a positive family history. In a large US study involving 1,032 PBC patients across 23 tertiary referral centers for liver disease matched with 1,041 controls, PBC occurrence in a first-degree relative was reported by $5.9 \%$ of cases and $0.5 \%$ of controls $(P<0.001)$. Familial PBC was reported most often in mothers $(1.7 \%)$ and sisters $(4.3 \%)$ compared to controls $(P<0.001){ }^{6}$ Multiple logistic regression showed that a family history of $\mathrm{PBC}$ in a first-degree relative was significantly associated with disease risk, with an adjusted odds ratio of 10.7 ( $95 \%$ confidence interval (CI) 4.227.3). ${ }^{6}$ Other associated risk factors include concurrent autoimmune disease, lifestyle factors such as past or current cigarette smoking, infectious triggers (particularly urinary and vaginal infections), and environmental influences such as toxic and chemical exposures (including nail polish and hair dye)..$^{5-8}$ Reports on the role of smoking, estrogens, or gravidity in promoting PBC are conflicting. Although some studies have documented risks, ${ }^{6,7,9}$ a large recent population-based study found no association of PBC with smoking, age at menarche or first pregnancy, or gravidity. ${ }^{10}$ Prevalent coexisting autoimmune conditions include Sjögren syndrome, scleroderma, and Hashimoto thyroiditis. 4

\section{Diagnosis and testing}

PBC diagnosis requires two of the three following objective criteria: 1) biochemical evidence of cholestasis based primarily on elevated level of serum ALP ( $>1.5$ times $(x)$ the upper limit of normal, ULN); 2) presence of serum AMA (titers $\geqslant 1: 40$ ); and 3 ) liver histology characterized by nonsuppurative cholangitis and interlobular bile duct destruction. $3,5,11$ AMA-positive patients with normal liver biochemistries should have yearly laboratory monitoring for the development of cholestasis. ${ }^{11}$ In patients who are AMA negative and have liver biopsy findings of possible PBC (or PSC), genetic testing for $A B C B 4$ (encoding the canilicular phospholipid transporter) deficiency should be considered. ${ }^{11,12}$ Family members (particularly female first-degree relatives) should be screened for PBC by testing serum ALP, and elevations should prompt checking AMA. ${ }^{3}$

\section{PBC overlap with autoimmune hepatitis}

A small subgroup of patients demonstrates features of both PBC and autoimmune hepatitis (AIH). A majority have positive AMA serology with histologic features of AIH and show an excellent response to steroid therapy. Another group of patients frequently classified with overlap have negative AMA serology but test positive for anti-smooth muscle antibody (ASMA) \pm antinuclear antibody (ANA) and show histologic features of PBC. This condition may be regarded as an AMA-negative form of PBC and is also referred to as immune cholangiopathy or autoimmune cholangitis. The Paris criteria can be used to diagnose PBC-AIH overlap syndrome. ${ }^{13}$

\section{Natural history and disease progression}

As aforementioned, PBC is a progressive disorder that advances variably among individuals and can span over several decades. PBC patient survival appears significantly decreased compared to age- and sex-matched controls, even with the exclusion of liver-related deaths. Median survival has been reported at 9.3 years following diagnosis. ${ }^{14}$ Irrespective of symptoms, patients with early PBC not treated with ursodeoxycholic acid (UDCA) have a shorter survival compared to healthy controls. ${ }^{3,14}$ Median time from diagnosis to symptom appearance is $2.0-4.2$ years, and median survival beyond the onset of symptoms has been reported at 5-8 years. $3,14,15$ Histologic stage has been shown to predict survival in $\mathrm{PBC}^{3}$ Without effective therapy, the disease appears to advance by approximately one stage every 1.5 
years, and the median time to developing extensive fibrosis is 2 years. ${ }^{16,17}$

\section{Treatment}

UDCA demonstrates anti-cholestatic and anti-fibrotic effects and is the primary pharmacotherapy used for PBC. The compound neutralizes toxic bile acids retained in the liver and significantly decreases biochemical markers including serum bilirubin and ALP. ${ }^{18}$ Additional improvements in serum aminotransferases, GGT, plasma IgM concentration, and total cholesterol have been noted. ${ }^{18}$ UDCA delays histologic disease progression and improves the natural history and overall prognosis of $\mathrm{PBC}$, particularly in patients showing response to the drug. ${ }^{17,19,20}$ UDCA has been shown to decrease the risk of developing esophageal varices, ${ }^{21}$ and long-term treatment over 4 years appears to significantly improve survival free of LT compared to placebo. ${ }^{22}$ A Cochrane Database Systematic Review (1,447 patients, 16 randomized clinical trials) showed that UDCA had a beneficial effect on histologic disease progression, but it did not support favorable UDCA effects on all-cause mortality, LT, fatigue, or pruritus. ${ }^{18}$

UDCA is generally safe and well-tolerated in pre- and postLT patients. ${ }^{3,18,23}$ A standard dosing regimen of $13-15 \mathrm{mg} / \mathrm{kg} /$ day is recommended for PBC patients with abnormal liver enzyme values (regardless of symptoms or histologic stage) and should be continued indefinitely. ${ }^{3}$ Higher UDCA doses (23-25 mg/kg/day) compared to standard doses do not appear to have significant added benefits in improving symptoms, biochemistries (aspartate aminotransferase (AST) and ALP), Mayo risk score, or duodenal bile acid enrichment. ${ }^{24}$

Liver biochemistries should be performed every 3-6 months, and a majority (90\%) of laboratory improvement is expected within 6-9 months. ${ }^{3}$ Patients with a Mayo risk score $<4.5(P<0.04)$ and/or serum ALP $<2$-fold ULN $(P<0.04)$ after 6 months of UDCA therapy appear more likely to have a positive response to UDCA over a 2 year period. ${ }^{24}$ Observational studies demonstrate that biochemical response to UDCA in PBC correlates favorably with long-term outcomes and survival without $\mathrm{LT}^{24,25}$ Incomplete biochemical response to UDCA, seen in up to $40 \%$, can identify patients at higher risk for disease progression. ${ }^{5}$ The biochemical criteria that most appropriately define UDCA treatment response are debated and include: ALP $<3 \times$ ULN, AST $<2 \times$ ULN, and normal bilirubin after 1 year of UDCA; ${ }^{26}$ ALP and AST $\leqslant 1.5 x$ ULN with bilirubin $\leqslant 1 \mathrm{mg} / \mathrm{dL}$ after 1 year of UDCA; ${ }^{27}$ ALP decline $>40 \%$ from baseline or to normal after 1 year of UDCA; ${ }^{25}$ ALP $\leqslant 1.67 \times$ ULN (with histologic endpoint defining nonresponse as a one-stage increase in fibrosis) or ALP $\leqslant 1.76$ (with histologic endpoint defining nonresponse as a two-stage increase in fibrosis) after 2 years of UDCA; ${ }^{28}$ and normalization of abnormal bilirubin and/or albumin levels after 1 year of UDCA. ${ }^{29}$ Patients with optimal biochemical measures, defined as ALP $\leqslant 1.67 x$ ULN and bilirubin $\leqslant 1 \mathrm{mg} / \mathrm{dL}$ following 1 year of UDCA treatment, were least likely to develop adverse clinical endpoints of ascites, encephalopathy, varices, LT, or death over 2 subsequent years compared to subjects with higher biochemical values. ${ }^{30}$ In addition, ductopenia ( $>50 \%$ loss) on baseline liver biopsy appeared to be a predictive factor of biochemical response to UDCA and histologic progression over extended followup. ${ }^{28}$ Patient compliance and superimposed liver disorders should be considered, and bile acid sequestrants can be added in the setting of suboptimal UDCA response. ${ }^{11,16}$

\section{Disease course and prognosis}

A retrospective analysis $(n=216)$ showed that PBC patients who were symptomatic at disease onset were more often female and of younger age with higher ALP and aminotransferase elevations compared to an asymptomatic group, despite similar autoantibody profiles and histologic disease stage. Symptomatic patients were less likely to respond to UDCA and progressed more frequently and more rapidly to cirrhosis and its associated complications, including ascites, esophageal variceal hemorrhage, hepatocellular carcinoma, LT-listing or surgery, or death due to liver failure. ${ }^{20}$ Incomplete UDCA response, inconsistent UDCA treatment, and advanced histologic disease stage are among risk factors for hepatic decompensation in PBC. ${ }^{31}$

Many patients (50-65\%) are now diagnosed in asymptomatic phases, reflecting increased awareness and testing for PBC. ${ }^{4}$ Treatment with UDCA, particularly for early-stage but also for late-stage PBC, has improved prognostic data compared to decades ago when no medical therapy was available. ${ }^{32,33}$ Long-term UDCA has an important long-term therapeutic effect, particularly for patients with nonadvanced, noncirrhotic disease. ${ }^{34}$ Up to $40 \%$ of patients diagnosed with early-stage PBC and initiated promptly on UDCA can remain at an early stage for at least 20 years from diagnosis. ${ }^{8}$ Survival in UDCA-treated patients is better than in untreated patients and greater than that predicted by the Mayo model. ${ }^{35}$ Prognostic factors of survival include serum bilirubin and albumin concentrations and the presence of cirrhosis. ${ }^{22,34,36}$ Fewer LTs and longer survival periods for PBC have been reported. ${ }^{37}$

\section{Primary sclerosing cholangitis}

PSC is an idiopathic cholestatic hepatobiliary disease characterized by chronic inflammation, progressive fibrosis, and stricturing of medium and large-sized extrahepatic and/or intrahepatic bile ducts (Fig. 3-4). ${ }^{38}$ Continuous destruction yields bile duct narrowing and eventual obliteration with disappearance of small bile ducts and diffuse, multifocal biliary strictures. Segmental bile duct dilation proximal to areas of stricture creates a characteristic cholangiographic appearance of beading (Fig. 5). Chronic inflammation leads to fibrosis of the hepatic parenchyma and biliary tree. PSC

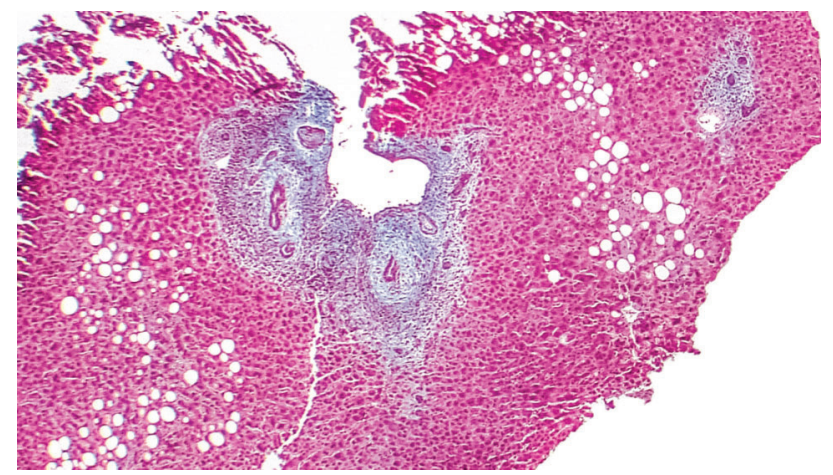

Fig. 3. Trichrome, X40; Liver Biopsy. Low power view demonstrating a focal lesion typical for primary sclerosing cholangitis. Periductular layered fibrosis (characteristic "onion skin" pattern) is seen with edema and inflammation surrounding the interlobular bile ducts in the center of the field. A normal portal area with bile ducts is seen in the upper right corner of the image. 


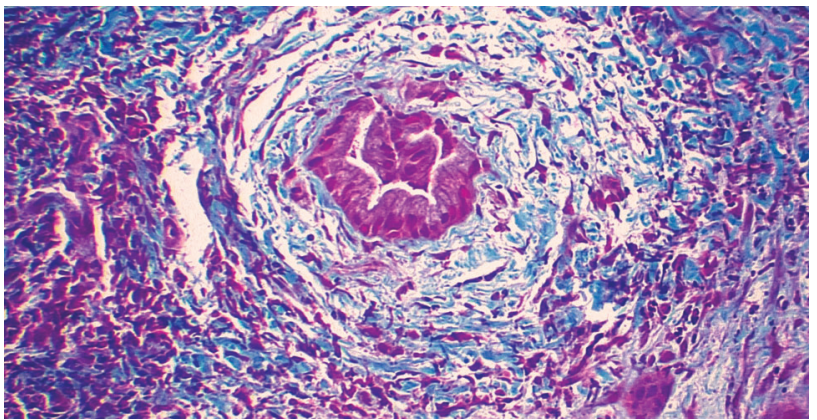

Fig. 4. Trichrome, X400; Liver biopsy. Typical focal lesion of primary sclerosing cholangitis demonstrating "onion skin" concentric fibrosis and chronic periductular inflammation. Notice significant edema in this relatively early phase of fibrosis.

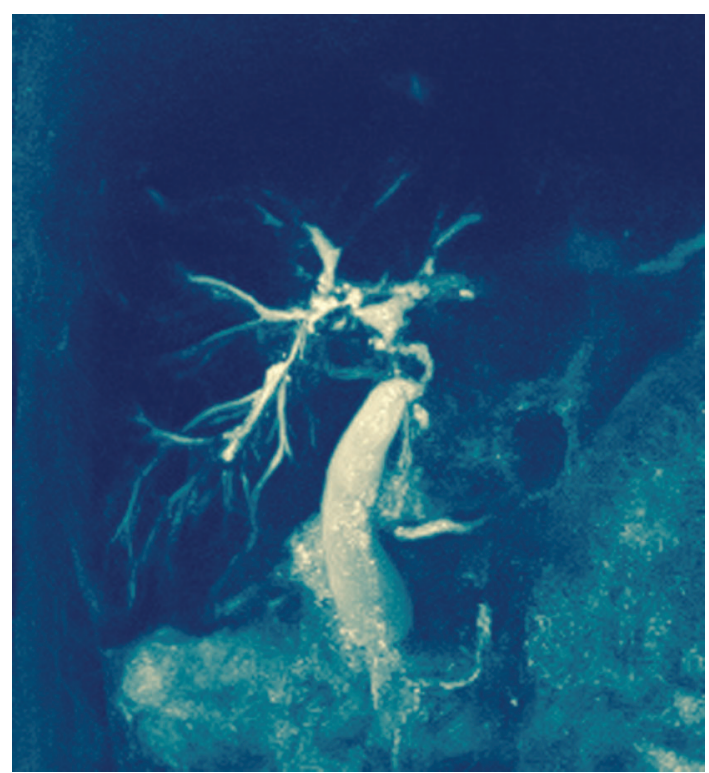

Fig. 5. Magnetic resonance cholangiogram in a patient with primary sclerosing cholangitis demonstrating characteristic findings of multifocal biliary strictures with intervening dilation and areas of sacculation.

typically progresses slowly over 10-15 years, eventually leading to biliary cirrhosis and premature death due to decompensated liver disease in a majority of patients. Additional complications of PSC include hepatic osteodystrophy, dominant bile duct strictures, recurrent cholangitis, and disease-associated malignancies including hepatobiliary (particularly cholangiocarcinoma), pancreatic, and colorectal (particularly with inflammatory bowel disease, IBD) cancers. PSC has rarely been associated with multifocal fibrosclerotic disease such as mediastinal, retroperitoneal, and periureteral fibrosis.

\section{Epidemiology}

PSC has a male predominance $(2: 1)$ and can occur at any age with a diagnostic peak at $30-40$ years. ${ }^{11,39}$ Women tend to be diagnosed later at an average age of approximately 45 years. ${ }^{40}$ The incidence and prevalence of PSC vary widely and have been estimated to range from 0 to 1.3 per 100,000 inhabitants/year and from 0 to 16.2 per 100,000 inhabitants, respectively. ${ }^{2}$

\section{Etiology}

The etiology of PSC is not fully understood, but it appears to be a heterogeneous and multifactorial disorder with genetic, immune-mediated, and other contributions. Although the genetic predispositions are not well-understood, the strongest risk factor is linked to human leukocyte antigens (HLAs) including major histocompatibility complex (MHC) genes encoded on chromosome $6 .^{41,42}$ Sixteen risk genes have been reported, comprising $<10 \%$ of approximate overall PSC susceptibility. ${ }^{42}$ Described genetic associations (for example, with HLA and fucosyltransferase 2) may be influenced by environmental triggers. ${ }^{42-48}$ PSC has been linked with a variety of factors associated with abnormal humoral and cellmediated immunity and can coexist with other autoimmune conditions such as IBD, thyroid disorders, type 1 diabetes mellitus, and celiac disease. ${ }^{48,49}$ Little is known about the nongenetic risk factors for PSC, although patients are usually nonsmokers. ${ }^{50-53}$ Translocation of intestinal bacteria or toxins across inflamed colonic mucosa into the portal circulation may result in hepatobiliary inflammation and can lead to the pathologic and cholangiographic appearance of PSC. ${ }^{39}$

There is currently no specific marker for PSC disease or severity, although the prevalence of perinuclear antineutrophil cytoplasmic antibodies ( $p$-ANCA) has been reported to range from $33-85 \%$ in patients with PSC and $40-87 \%$ in patients with ulcerative colitis (UC). ${ }^{54-57}$ These anti-neutrophil specific antibodies, found at high frequencies and almost exclusively in IBD, PSC, and AIH, are also called "atypical p-ANCA" due to their staining pattern under indirect immunofluorescence microscopy that is distinct from the "classical p-ANCA" associated with microscopic polyangiitis. ${ }^{55}$ P-ANCA has been reported in 0 to $<10 \%$ of healthy controls. ${ }^{54,58} \mathrm{~A}$ high degree of ANCA specificity (predominantly isotypes IgG1 and IgG3) has been detected for both PSC and UC. ${ }^{59,60}$ Other nonspecific autoantibodies in PSC include ANA, ASMA, anticardiolipin antibody, and rheumatoid factor ${ }^{61}$ Elevated levels of circulating immune complexes ${ }^{62}$ and hypergammaglobulinemia (preferentially elevated serum IgM in $45 \%$ of patients elevated IgG in some cases) have also been reported. 39,48

The risk of PSC is higher in patients with a family history of the disease. ${ }^{63}$ Disease prevalence in first-degree relatives of PSC patients has been reported at $0.7 \%$, with a prevalence of $1.5 \%$ among siblings. ${ }^{64}$ First-degree relatives of PSC patients without IBD appear to be at increased risk for developing IBD, particularly UC. ${ }^{65}$ P-ANCA has also been reported in $25 \%$ and $30 \%$ of unaffected first-degree relatives of PSC and UC patients, respectively. ${ }^{66}$

\section{PSC and IBD}

A close association exists between PSC and IBD. ${ }^{38,40,67}$ The most frequently associated IBD type is UC, seen in approximately $70-86 \%$ of PSC patients. ${ }^{38,68,69}$ The prevalence of PSC in UC has been reported to range from $2.4-7.4 \% .{ }^{70}$ The median interval between initial IBD diagnosis and subsequent PSC is 6.9 years, ${ }^{71}$ although the diagnosis of PSC can be made prior to that of $I B D^{72}$ or even several years after proctocolectomy for UC. ${ }^{63}$ IBD can also recur or manifest de novo after LT for PSC. ${ }^{73}$ IBD in PSC runs its course 
Marchioni Beery R.M. et al: Review of PBC \& PSC in women's health

independently of the liver disease. There is a high prevalence of pancolitis in cases of PSC-IBD, although disease activity in this group is often mild and occasionally asymptomatic. ${ }^{67,72}$ PSC-IBD is also frequently associated with rectal sparing and backwash ileitis and may represent a distinct IBD phenotype. ${ }^{67,74}$ Proctocolectomy as a surgical treatment for UC has not been shown to influence liver biochemistries, histology, or survival in PSC patients. ${ }^{63}$

\section{Diagnosis}

PSC is commonly found incidentally, and up to $50 \%$ of patients are asymptomatic at the time of diagnosis. ${ }^{75}$ Initial presentation in symptomatic patients typically includes fatigue, pruritus, weight loss, and right upper quadrant abdominal pain. Cholangitis is an uncommon first manifestation in the absence of prior intervention such as biliary surgery or endoscopic retrograde cholangiopancreatography (ERCP).

If abdominal ultrasound and AMA are nondiagnostic in the initial cholestasis workup, further imaging should be pursued. Magnetic resonance cholangiopancreatography (MRCP) is the diagnostic imaging test of choice for suspected PSC. MRCP is non-invasive and avoids radiation exposure, although early PSC may be missed using this modality. Endoscopic ultrasound can be used as an alternative to MRCP in evaluating distal biliary tract obstruction. ${ }^{11}$ ERCP was once considered the diagnostic gold standard for PSC, but it is an invasive test requiring radiation and has been linked with complications that can require hospitalization in $>10 \%$ of PSC patients undergoing the procedure. ${ }^{76}$ Although not recommended as a first-line modality, ERCP can be employed in some circumstances, such as in establishing large-duct PSC with suboptimal MRCP views. Characteristic cholangiographic findings include diffuse multifocal bile duct strictures and segmental dilatation yielding a beaded appearance. Liver biopsy is not required for diagnosis but is recommended in patients with normal cholangiographic findings to exclude small-duct PSC and in patients with disproportionately elevated aminotransferases to exclude overlap syndrome.

Associated conditions for consideration, as described briefly below, include small-duct PSC, PSC overlap conditions including AIH and autoimmune pancreatitis (AIP), and IgG4associated sclerosing cholangitis. Causes of secondary sclerosing cholangitis that resemble PSC but have a known pathologic origin must be excluded. Such involve surgical injury or blunt abdominal trauma, toxic consequence of intraarterial chemotherapy, intraductal stone disease, and recurrent pancreatitis. Other secondary causes include recurrent pyogenic cholangitis, eosinophilic cholangitis, acquired immunodeficiency syndrome cholangiopathy, portal biliopathy, and ischemic cholangiopathy, among others. ${ }^{77}$

\section{Small-duct PSC variant}

Small-duct PSC is characterized by clinical, histologic, and biochemical evidence of PSC with a normal cholangiogram ${ }^{11}$ and is confirmed with liver biopsy. ${ }^{78}$ The entity, seen in $5.8 \%$ of PSC patients, has been described as an earlier stage or mild variant of large-duct disease and generally has a more favorable prognosis relative to large-duct PSC. ${ }^{78}$ An increased survival to death or LT has been reported in small-duct compared with large-duct PSC. ${ }^{79}$ Some patients initially diagnosed with small-duct PSC, however, can develop classic PSC and end-stage liver disease with consequent need for $\mathrm{LT}^{78,80}$

\section{PSC overlap conditions}

Conditions with features of both PSC and other immunemediated conditions, known as PSC overlap syndromes, include AIH and AIP. In PSC-AIH overlap, histologic features of AIH and cholangiographic features of PSC are seen. ${ }^{81}$ Elevated IgG autoantibodies and interface hepatitis are often present. ${ }^{82}$ Common serologic abnormalities include positive ASMA and ANA (in up to $75 \%$ of patients) and elevated IgM levels (in up to $50 \%$ of patients). Up to $60 \%$ of PSC patients may have elevated IgG4. ${ }^{38}$

Management of PSC-AIH may be challenging. Combination treatment for PSC-AIH with UDCA and immunosuppressant therapy (prednisone \pm azathioprine or 6-mercaptopurine) is recommended but not supported by data from large, randomized controlled trials. ${ }^{11,83}$ In a small number of patients with PSC-AIH overlap, UDCA in addition to corticosteroids appeared beneficial with a significant reduction in AST over a 5-year treatment course; no significant changes were noted in ALP or GGT. These patients with PSC-AIH overlap appeared to have a more favorable cumulative survival compared to patients with classic PSC. ${ }^{81}$

AIP is a rare, systemic fibrotic disorder characterized by generalized pancreatic enlargement, pancreatic ductal narrowing/strictures, biliary strictures, and elevated serum IgG4 levels. ${ }^{84}$ Cases without pancreatic duct involvement are termed IgG4-associated cholangitis. Increased serum IgG4 levels with an infiltration of IgG4+ plasma cells into bile ducts and liver tissue results from an autoimmune or idiopathic mechanism. Guidelines advocate checking IgG4 levels to exclude IgG4-associated sclerosing cholangitis in all patients with suspected PSC. ${ }^{38}$ A trial of steroid therapy is recommended in this group, as normalization of liver enzymes and improvement or resolution of biliary strictures frequently occur. $^{38,85}$

\section{Disease course and progression}

Asymptomatic PSC patients appear to have a decreased average survival relative to age- and sex-matched controls. ${ }^{40,86}$ The natural history of PSC is highly variable, with reported average survival rates from diagnosis to death or LT ranging from $12-18$ years. ${ }^{2,68,87}$ A recent population-based study from the Netherlands reported an even higher median survival time of 21.3 years. ${ }^{79}$

\section{PSC and malignancy}

Patients with PSC are at increased risk for developing such malignancies as hepatobiliary (cholangiocarcinoma, hepatocellular carcinoma, and gallbladder carcinoma), colorectal, and pancreatic cancers (Table 1 ) that require dedicated attention alongside age-appropriate cancer screening protocols.

\section{Therapy}

There is currently no effective therapy for PSC that affects mortality other than LT for end-stage disease. Recurrent PSC is a risk even after $\mathrm{LT}^{88}$ and median survival without a second LT in recurrent PSC is reported at 9.1 months. ${ }^{89}$ 
Table 1. Malignancy screening in primary sclerosing cholangitis

\begin{tabular}{|c|c|}
\hline Cholangiocarcinoma & $\begin{array}{l}\text { - Investigation for CCA should be pursued with clinical suspicion based on: }{ }^{38} \\
\text {-Altered liver biochemical parameters } \\
\text {-Development of dominant biliary stricture } \\
\text {-Decline in constitutional performance status } \\
\text {-Clinical symptoms such as jaundice, abdominal pain, or weight loss } \\
\text { Suggested screening approach includes: }{ }^{38} \\
\text {-MR imaging (MRI/MRCP) of liver } \\
\text {-Measurement of serum CA } 19-9 \\
\text {-ERCP for investigation of dominant stricture or elevated CA 19-9; biliary biopsy and brush } \\
\text { cytology with molecular testing by FISH analysis where available }\end{array}$ \\
\hline Colorectal Cancer & $\begin{array}{l}\text { - Colonoscopy with biopsies at initial PSC diagnosis and thereafter as follows: }{ }^{11,38} \\
\text {-Surveillance colonoscopy with biopsies every } 1 \text { year for PSC patients who have IBD or are } \\
\text { post-liver transplantation }{ }^{11,191} \\
\text {-Surveillance colonoscopy with biopsies every } 5 \text { years in PSC patients without IBD }{ }^{192} \\
\text { - UDCA is currently not recommended for chemoprevention in PSC-UC }{ }^{38}\end{array}$ \\
\hline Gallbladder Cancer & $\begin{array}{l}\text { Abdominal ultrasound yearly } 11,38 \\
\text {-Detection of mass lesion(s) in the gallbladder should prompt cholecystectomy in } \\
\text { appropriate surgical candidates }{ }^{11,38}\end{array}$ \\
\hline $\begin{array}{l}\text { Hepatocellular } \\
\text { Carcinoma }\end{array}$ & $\begin{array}{l}\text { - Abdominal ultrasound every } 6 \text { months }{ }^{193} \\
\text { - } \quad \text { Measurement of serum alpha-fetoprotein can be considered }\end{array}$ \\
\hline
\end{tabular}

Abbreviations: CCA (cholangiocarcinoma); MRI (magnetic resonance imaging); MRCP (magnetic resonance cholangiopancreatography); CA (carbohydrate antigen); ERCP (endoscopic retrograde cholangiopancreatography); FISH (fluorescence in situ hybridization); PSC (primary sclerosing cholangitis); IBD (inflammatory bowel disease); UDCA (ursodeoxycholic acid); UC (ulcerative colitis).

Data to support the use of UDCA in PSC have been controversial. A Cochrane Database Systematic Review (eight randomized clinical trials; 592 PSC patients reporting a range of UDCA doses) found that, although UDCA appeared safe and well-tolerated, it may not significantly reduce the risk of death, histologic disease progression, cholangiographic deterioration, or clinical decompensation (encephalopathy, varices, ascites, or LT) compared to placebo or no intervention. ${ }^{23} \mathrm{~A}$ subsequent meta-analysis including eight randomized trials (five using standard-dose UDCA and three using high-dose UDCA) and 567 PSC patients showed no significant difference in pruritus, fatigue, histologic stage progression, cholangiocarcinoma, or mortality compared to placebo or no intervention. ${ }^{90}$ Furthermore, high-dose UDCA (28-30 mg/kg/day) was not associated with a survival advantage and was linked with an increased risk of serious adverse events. ${ }^{91}$

Although UDCA can improve liver biochemistries and surrogate prognostic markers, its use has not shown survival benefit, ${ }^{11}$ and it is not recommended as a medical therapy in PSC. ${ }^{38}$ Treatment with immunosuppressant and anti-fibrotic drugs has not demonstrated consistent improvement in disease activity or clinical outcomes in classic PSC. Many agents have failed to demonstrate sustained benefit, including cyclosporine, tacrolimus, methotrexate, pentoxifylline, D-penicillamine, colchicine, cholestyramine, and nicotine. ${ }^{92}$ As aforementioned, certain PSC subgroups with overlap features appear to benefit from corticosteroid and immunosuppressant therapy. ${ }^{38,81,85,93}$

\section{Clinical manifestations of PBC and PSC}

Common symptoms of PBC and PSC include fatigue, pruritus, and upper abdominal discomfort, although over $50 \%$ of patients are asymptomatic at diagnosis. ${ }^{2}$ Fat-soluble vitamin deficiency may be detected, particularly with advanced liver disease.

\section{Fatigue}

Fatigue is experienced in up to $78 \%$ of patients with PBC. ${ }^{3}$ It has also been described in PSC although less extensively studied. The symptom is nonspecific, multifactorial, and potentially incapacitating. Conditions such as anemia, diabetes, hypothyroidism, or depression should be considered and excluded. ${ }^{11}$ The etiology of the fatigue has not been fully elucidated, ${ }^{3}$ and there is no well-established treatment. ${ }^{4}$ It has been linked to abnormal corticotrophin-releasing hormone ${ }^{94}$ and serotonin neurotransmission systems, ${ }^{95}$ although fluvoxamine (a selective serotonin reuptake inhibitor and $\sigma 1$ agonist), fluoxetine (a selective serotonin reuptake inhibitor), and ondansetron (a selective 5-HT3 receptor antagonist) do not appear effective. ${ }^{96-98}$ Oral antioxidant supplementation (vitamins A, C, E, and selenium) has shown no beneficial effect in reducing fatigue. ${ }^{99}$ In an open-label study, modafinil (a central nervous system stimulator) was shown to improve excess daytime somnolence and fatigue severity. ${ }^{100}$ While most patients $(66 \%)$ were able to tolerate modafinil over 2 months, others experienced significant headaches that resolved immediately with drug discontinuation. ${ }^{100}$ UDCA has not been shown to improve fatigue in PBC. ${ }^{3}$ Severe fatigue may interfere with quality of life, worsen with advanced cirrhosis, and contribute to a decline in overall survival. ${ }^{101}$

Supportive care measures, such as minimizing potential hindrances to sleep (e.g., caffeine intake in evening) and avoiding factors that promote autonomic nervous system dysfunction (e.g., excess antihypertensive, antihistamine, or sedative medications), should be employed. In addition, psychological support and the establishment of healthy coping mechanisms should be encouraged. LT is not recommended for fatigue alone in the absence of other indications. $^{11}$ 


\section{Pruritus}

Pruritus is variably reported in cholestasis. Its natural history, related pathogenesis, and molecular mechanisms are under continued investigation. ${ }^{95,102}$ Contributing factors include bile acid stasis as well as accumulation of biliary compounds and pruritogens into the systemic circulation and peripheral tissues. ${ }^{3}$ Increased opioidergic and serotoninergic neurotransmission and the influence of estrogens/progesterones have also been described. ${ }^{3,103,104}$ Additionally, lipophospholipase autotaxin and its product, lysophosphatidic acid (a potent neuronal activator), have been implicated. ${ }^{102,104,105}$ Histamine unlikely contributes to cholestatic pruritus. ${ }^{102,104}$ Although pruritus is not regarded as a prognostic factor, it can decrease quality of life and can contribute to depression and sleep deprivation. $8,102,106$ UDCA generally does not relieve pruritus in PBC. ${ }^{3}$ A stepwise treatment approach includes: cholestyramine as a first-line agent; rifampicin as a second-line agent; naltrexone as a thirdline agent; and sertraline as a fourth-line agent. ${ }^{11}$ In refractory cases, experimental treatments and referral to specialized centers can be considered, and such methods as extracorporeal albumin dialysis, plasmapheresis, and nasobiliary drainage may be attempted. ${ }^{11}$ UV-B therapy has also been suggested. ${ }^{102}$ LT for disabling, refractory pruritus is effective but should only be considered if all other options are unsuccessful. ${ }^{11}$

\section{Fat-soluble vitamin deficiency}

Malabsorption, steatorrhea, and fat-soluble vitamin deficiencies are uncommon except in cases of advanced liver disease and long-standing, severe cholestasis. ${ }^{107,108}$ Steatorrhea and dietary fat malabsorption, predominantly due to decreased bile acid secretion into the small intestinal lumen, can predispose to weight loss. As luminal bile acid levels in severe cholestasis are below the critical concentration required for micelle formation and subsequent lipid absorption, clinically relevant fat-soluble vitamin ( $A, D, E, K$ ) deficiencies may exist. ${ }^{16,109}$ Exocrine pancreatic insufficiency and rarely celiac disease may be associated and should be excluded. ${ }^{16,92,110}$ Deficiencies in vitamins $A, D, E$, and $K$ have been reported in $33.5 \%, 13.2 \%, 1.9 \%$, and $7.8 \%$ of PBC patients, respectively. ${ }^{109}$ Vitamin A deficiency appears to be significantly associated with advanced PBC stage, decreased cholesterol, and increased Mayo risk score. Low serum albumin level, high Mayo risk score, and elevated total bilirubin have been shown to be independently associated with vitamin D deficiency. Relatively fewer patients have vitamin E or K deficiencies. ${ }^{109}$ Blood testing to determine fatsoluble vitamin levels should be performed at the time of PBC or PSC diagnosis and periodically thereafter, especially in the setting of advanced cholestasis. Vitamin supplementation should be administered as necessary in cases of steatorrhea and clinical deficiency..$^{92,107-109}$

\section{Clinical consequences of PBC and PSC relating to women's health}

\section{Metabolic bone disease}

MBD is a major focus in women's health and is especially important in post-menopausal females, who are also most commonly diagnosed with PBC. MBD with premature cortical thinning is a recognized complication of chronic liver disease and is seen in a majority of patients, particularly those with advanced stages and high degrees of cholestasis. ${ }^{3,11}$ Ranging from osteopenia (least severe) to osteoporosis to osteomalacia (most severe), the skeletal conditions are broadly termed "hepatic osteodystrophy" in the setting of chronic liver disease.

MBD has been documented in up to $77 \%$ of patients with advanced PBC or PSC. ${ }^{111}$ Although often asymptomatic, MBD can result in recurrent fractures, impaired quality of life, augmented economic burden, and increased morbidity and mortality. ${ }^{112}$ Limited physical activity (due to fatigue and the burdens of chronic illness), nutritional deficiencies, and perimenopausal estrogen decline can all negatively impact bone mass in female PBC and PSC patients.

The exact mechanism of MBD in chronic cholestatic liver disease is not distinctly defined, and its etiology appears to be multifactorial. Retained bilirubin in advanced cholestasis negatively impacts osteoblast function and leads to imbalanced patterns of bone metabolism. ${ }^{113}$ Low bone formation and increased bone turnover rates have been implicated in the process ${ }^{113-115}$ and predispose to fracture risk. ${ }^{115}$ Some studies have reported similar age- and sex-adjusted bone mineral density (BMD) values for males and females with $\mathrm{PBC}$ and PSC, suggesting a common etiologic factor. ${ }^{111,116,117}$ Other reports have demonstrated that postmenopausal cirrhotic women are at a significantly higher risk for longitudinal bone mineral loss relative to age- and sex-matched healthy controls; this difference was not detected in cirrhotic males, however, whose changes in bone mineral content over time were comparable to healthy male controls. ${ }^{118}$ As osteoporosis severity appears to parallel the natural progression of PBC and PSC, optimizing bone health is particularly important in patients with advanced disease.

Hepatic osteodystrophy may be influenced by vitamin and mineral abnormalities, specifically for patients with advanced cholestasis and steatorrhea who are prone to fat-soluble vitamin depletion. Although serum concentrations of calcium and physiologically active vitamin D metabolites (25-hydroxyvitamin $D$ and 1,25-dihydroxyvitamin D) are typically normal, ${ }^{92}$ vitamin $\mathrm{D}$ deficiency can be present in cases of malabsorption and may be intensified with the use of cholestyramine and similar agents. Deficiency of vitamin K, known to promote the conversion of protein-bound glutamate residues to $\gamma$-carboxyglutamate in a variety of bone proteins such as osteocalcin, can lead to undercarboxylated or deficient osteocalcin that may, in turn, be associated with bone fragility. ${ }^{119}$

Retained lithocholic acid (LCA) in cholestasis damages osteoblasts and acts as a mild vitamin $D$ analogue that interferes with the vitamin $D$ receptor pathway, leading to decreased expression of genes involved in bone formation. ${ }^{120}$ The detrimental effects of LCA could be worse in patients with low albumin, as seen in advanced cholestasis. In vitro, UDCA has been shown to promote osteoblast differentiation and mineralization and to neutralize the toxic effects of bilirubin and LCA on osteoblastic cells. ${ }^{121}$ Additional factors influencing BMD include hormonal deficiencies (such as estrogen, testosterone, and insulin-like growth factor-1), trace element deficiencies (including zinc, copper, and iron), hepcidin deficiency and iron overload conditions (including hereditary hemochromatosis, thalassemia, sickle cell anemia, and African hemosiderosis), renal tubular acidosis, parathyroid dysfunction, and immunosuppression, among others. ${ }^{115,120,122-128}$ 
Osteoporosis prevalence appears greater in women with $\mathrm{PBC}$ versus age- and sex-matched controls. ${ }^{129-131}$ Higher fracture risk has also been reported in PBC patients compared with the general population and patients with other chronic liver diseases. ${ }^{129,130,132}$ Fracture prevalence in PBC ranges from approximately $10-21 \% .{ }^{115}$ Factors that increase the osteoporotic risk in PBC, as in the general population, include advanced age and low body mass index ${ }^{129,130,133,134}$ Other predisposing risk factors for osteoporosis in female $\mathrm{PBC}$ patients include postmenopausal state, vitamin $D$ deficiency, and longer duration ( $>4$ years) of PBC. ${ }^{130,131}$ PBC severity may impact osteoporotic risk and severity of MBD, although this has been debated. ${ }^{114,129,130,133,134}$ One study documented a 5.4-fold increased risk of osteoporosis in advanced PBC cases compared to those with less severe disease. ${ }^{133}$ Severity of low bone mass is associated with morbidity in PBC due to fractures, pain, and skeletal deformity. ${ }^{135}$ Severe bone disease fortunately appears to be decreasing in PBC patients, perhaps due to improvements in MBD screening and therapy. ${ }^{4}$

There are fewer studies of MBD in PSC relative to PBC. The incidence of osteoporosis in PSC is reported at $4-10 \%{ }^{38}$ Advanced age, low body mass index, and hypogonadism (influenced by low testosterone and estrogen decline) can contribute. ${ }^{112,115,116}$ In PSC-IBD patients, the rate of bone loss and risks for osteoporosis appear to increase with IBD duration; such may be explained by the use of corticosteroid therapy and the presence of inflammatory cytokines. ${ }^{116,136}$

Bone health is particularly vulnerable in the pre- and postLT settings. One of the most important factors in developing post-LT MBD is the degree of osteopenia at the time of LT surgery. Additionally, corticosteroid and immunosuppressant use (e.g., cyclosporine $A$ and tacrolimus), poor nutrition, and immobility can negatively impact post-LT BMD. ${ }^{115}$ MBD and fracture risk after LT in PBC and PSC are not only influenced by pretransplant low BMD but are also compounded by early, accelerated post-transplant bone loss. ${ }^{111}$ The greatest decline in bone loss appears in the first 3-6 post-operative months, ${ }^{115}$ and most fractures occur within the first postoperative year. ${ }^{115}$ BMD restoration has been demonstrated within the first $2-3$ years following LT. ${ }^{111,137}$ Successful LT appears to increase bone density over time, particularly in patients who achieve normal hepatic function and whose nutritional status and gonadal hormone levels improve after surgery. ${ }^{111,138}$

\section{Testing and therapeutic interventions for MBD}

Dual-energy X-ray absorptiometry (DEXA) testing is the gold standard for assessing BMD and should be performed in all newly diagnosed PBC and PSC cases and in settings of cirrhosis, fragility fracture, long-term glucocorticoid use ( $\geqslant 3$ months), and LT. ${ }^{11,38,135,139}$ Determinants of bone metabolism should be checked including serum calcium, phosphate, and 25-hydroxyvitamin D levels with measurement of free testosterone in males. ${ }^{115}$ In patients with a normal baseline DEXA, testing should be repeated every $2-3$ years to exclude the development of significant bone loss. ${ }^{115}$ Rescreening should be performed more frequently, up to yearly, in patients with profound cholestasis, prolonged or high-dose steroid exposure, or other individual risk factors for MBD and fractures. ${ }^{11,133,135}$

Regarding treatment, UDCA may not influence the rate of bone loss in PBC or PSC. ${ }^{140,141}$ Most therapies used to treat osteoporosis in the general population have been studied in PBC patients including bisphosphonates, hormone replacement therapy (HRT), calcitonin, and sodium fluoride. ${ }^{135,142-146}$ Bisphosphonate therapy is indicated for osteoporosis, fragility fractures, or prolonged exposure to glucocorticoids ( $\geqslant 3$ months) and may be considered at a T-score $\leqslant 1.5$ when accompanied by other risk factors. ${ }^{11}$ Parenteral bisphosphonates are preferred in patients with esophageal varices due to the potential risk of esophageal ulcers with oral formulations. ${ }^{38}$ There have been no controlled trials conducted on the use of bisphosphonates in PSC. HRT with estrogen can be considered to preserve bone health in older females with hepatic osteodystrophy and is advised for use in the settings of early menopause (age $<45$ years) and female hypogonadism in order to prevent osteoporosis and to reduce fracture risk. ${ }^{114,115}$ HRT appears to improve BMD and decrease the rate of bone loss in PBC. ${ }^{147-149}$ Although HRT is reserved for certain situations, it has not been routinely recommended for the treatment of MBD associated with cholestasis in females, ${ }^{11,115}$ as it has been linked with significant adverse events and has not shown significant beneficial effects on LT or liver-related morbidity or mortality in PBC. ${ }^{146}$ Some studies have demonstrated no significant changes in liver biochemistries, while worsening cholestasis has been reported in others. ${ }^{146-150}$ Transdermal estrogen evades first-pass hepatic metabolism and may reduce cholestatic potential of HRT. ${ }^{115,151}$ Other therapies for MBD such as raloxifene, calcitonin, and parathyroid hormone replacement can be considered, and administration should be directed by a bone specialist. ${ }^{115}$

\section{Hyperlipidemia and cardiovascular disease risk}

Cardiovascular disease is a leading cause of female death, and its associated risk with hyperlipidemia has been well-established in the general population. ${ }^{152}$ Despite the marked hypercholesterolemia common in PBC, patients do not appear to have an increased mortality risk due to atherosclerosis. ${ }^{153,154}$

\section{Lipid aberrations in cholestasis}

Serum lipid abnormalities are frequent in PBC and PSC. ${ }^{108,155}$ Decreased biliary lipid secretion contributes to profound hyperlipidemia, with notably high free cholesterol and phospholipids. ${ }^{154,156}$ The lipid aberrations are complex and can affect most lipoprotein (LP) classes but are largely attributed to LP-X, an abnormal low-density lipoprotein (LDL) particle (composed predominantly of phospholipids and unesterified cholesterol with low protein, cholesterol ester, and triglyceride components). The LDL associated with cholestasis is heterogeneous and may contain LP-Y (a large triglyceride-rich particle) in addition to LP-X, amongst more normal-appearing particles deplete in cholesterol esters and high in triglycerides. ${ }^{156}$ Excess triglyceride in cholestasis is primarily found in these two LDL fractions rather than in association with very-low-density lipoproteins (VLDLs). ${ }^{156}$

LP-X contributes to cholestatic hypercholesterolemia by way of its cholesterol content but bears anti-atherogenic properties that may actually decrease atherosclerotic risk. ${ }^{157,158}$ Interestingly, LP-X isolated from PBC patients has been shown to reduce LDL atherogenicity by preventing $\mathrm{LDL}$ oxidation and preserves the integrity of bovine aortic endothelial cells in culture (despite hypercholesterolemia). ${ }^{159}$ 
LP-X also promotes hepatic cholesterolgenesis and has been shown to reduce the hepatic suppression of cholesterol synthesis by increasing hepatic hydroxymethylglutaryl coenzyme A (HMG-CoA) reductase activity. ${ }^{158}$ Increased HMGCoA reductase enzyme mass (by about 2 -fold) has been demonstrated in cholestatic hepatic cells incubated with LP-X compared to control cells. ${ }^{160}$

Abnormalities in LP patterns vary depending on the histologic stage of disease and degree of hepatic dysfunction. Patients with early and intermediate PBC typically have mildly elevated LDL and VLDL levels with profoundly elevated highdensity lipoprotein (HDL) levels. ${ }^{154}$ Additionally, hepatic lipase inhibition and altered cholesterol esterification have been shown in later stages. ${ }^{153}$

\section{Hyperlipidemia and relationship to cardiovascular health}

Few prospective trials investigating cardiovascular events in PBC have been published. A prospective observational cohort study of 400 PBC patients found that the incidence of cardiovascular events (cerebrovascular and coronary) in PBC patients was similar to that of controls. Severe hypercholesterolemia (total cholesterol (TC) $>300 \mathrm{mg} / \mathrm{dL}$ ) was not associated with an increased risk of cardiovascular events, although it was associated with the presence of hypertension. ${ }^{154}$ A prospective study of 312 PBC patients observed for a median of 7.4 years reported that the incidence of death due to atherosclerosis was not statistically different from that of an age- and sex-matched US control population. ${ }^{161} \mathrm{~A}$ retrospective study examining a death registration database in the Netherlands over 14 years (from 1979-1992; including 596 deceased PBC subjects) found that 417 patients died from PBC-related complications as a primary cause of death, while 179 patients died with PBC as a secondary cause of death. Secondary causes of death in PBC were not significantly different using standardized mortality ratios and were related to the circulatory system in 61 patients (34\%), of which 23 patients $(13 \%)$ died of ischemic heart disease and 16 patients $(9 \%)$ died of an acute myocardial infarction. In this group, older patients (age $>60$ years) had significantly more deaths from vascular disease (i.e., of the arteries, arterioles, and capillaries) compared to younger patients. ${ }^{162}$

Limited data exist regarding hyperlipidemia and cardiovascular risks in association with PSC. A retrospective, continuous, longitudinal study of 157 PSC patients (42\% female) monitored serum lipid levels annually (for up to 6 years) and analyzed treatment effects of UDCA on lipid profiles. Liver biochemistries, including alanine aminotransferase, ALP, and total bilirubin, were significantly associated with TC levels, and only ALP was associated with LDL. Average values for TC, $L D L$, and triglycerides declined after 6 years by $8 \%, 18 \%$, and $7 \%$, respectively. High-dose UDCA treatment over 2 years significantly reduced TC and LDL (but not HDL) compared to placebo. PSC patients did not demonstrate an increased risk for coronary events. Coronary artery disease, reported with an incidence of $3 \%$, was not associated with baseline lipids or changes in lipid levels at followup. ${ }^{163}$

Another study analyzed lipid profiles in two PSC patient groups. The first group (56 patients: 22 with stage I+II and 34 with stage III+IV disease; 24 females) was participating in a randomized, placebo-controlled UDCA trial. The second group (38 females) included advanced PSC patients undergoing evaluation for LT. More patients in the first group showed elevated serum TC (41\%) and HDL (20\%), with only $2 \%$ demonstrating elevated triglycerides. TC levels correlated directly with bilirubin and were significantly lower in early versus late stages. In the second group, TC declined in inverse correlation to bilirubin, and triglycerides increased $(17 \%)$. Despite lipid abnormalities, no atherosclerosisrelated morbidity or mortality was reported. ${ }^{108}$

Data from a large prospective multicenter cohort study (1970-2004) of 678 PSC patients and 6,347 non-PSC ageand sex-matched controls linked with 3,139 first-degree relatives to PSC patients and 30,953 first-degree relatives to a matched comparison cohort was analyzed over 125,127 person-years of follow-up. Cardiovascular disease was diagnosed in 203 PSC patients, corresponding to a 3.34-fold increased relative risk (RR), with the highest estimated risk for diseases of the veins and lymphatics $(R R=6.95)$. Diseases of the arteries $(R R=5.61)$ and pulmonary heart disease or disorders of the pulmonary circulation $(R R=5.03)$ were also heightened. The RR was slightly elevated for cerebrovascular disease $(R R=1.74)$ and neutral for ischemic heart disease $(R R=0.90)$. First-degree relatives of PSC patients did not appear to be at higher risk for cardiovascular disease. ${ }^{164}$

\section{Lipid-related therapies}

As a result of dramatic, prolonged lipid derangements, cholesterol deposits can develop at bony prominences, tendon sheaths, and peripheral nerves (xanthomata) in addition to periorbital skin folds (xanthelasmata). Xanthomatous skin lesions, however, may not correlate with inappropriately advanced atherosclerosis or coronary disease. ${ }^{165}$ Large-volume plasmapheresis for management of xanthomas (particularly planar xanthomas on the hands and soles) is rarely employed but may be considered in cases causing pain or physical limitations. ${ }^{166}$

Lipid-lowering medications may be recommended for some patients based on individual risk factors but are not standard therapies in PBC or PSC. Recommended guidelines should be followed for appropriate risk stratification and management of dyslipidemia. ${ }^{167,168}$ Lifestyle modifications, including dietary and exercise counseling, should be provided. Lipid-lowering agents, such as statins and ezetimibe, appear safe when accompanied by close monitoring of liver biochemistries. ${ }^{4}$ Statins have been reported in small studies to reduce cholesterol and total bile acid levels in PBC patients. ${ }^{169-171}$ UDCA has been shown to significantly decrease TC levels at 1 and 2 years compared to placebo, without significantly influencing serum HDL and triglycerides. No severe side effects from UDCA were reported in this study. ${ }^{172}$ Of note, the dyslipidemia associated with cholestasis has been reported to improve after LT. ${ }^{173}$

Please refer to Table 2 for a summary of clinical management recommendations in PBC and PSC.

\section{Pregnancy-related issues, maternal health, and birth outcomes}

Chronic cholestatic liver diseases such as PBC and PSC can pose unique clinical challenges during pregnancy. The states are relatively rare, and there is limited literature surrounding the topics. Liver disease may initially manifest during pregnancy or may be an established diagnosis prior to pregnancy. Diagnosis and management of liver disease in 
Marchioni Beery R.M. et al: Review of PBC \& PSC in women's health

Table 2. Summary of management recommendations for two cholestatic liver disease

\begin{tabular}{|c|c|c|}
\hline & Primary biliary cirrhosis (PBC) & Primary sclerosing cholangitis (PSC) \\
\hline $\begin{array}{l}\text { Disease- } \\
\text { Specific } \\
\text { Medical } \\
\text { Therapy }\end{array}$ & $\begin{array}{l}\text { UDCA } 13-15 \mathrm{mg} / \mathrm{kg} / \mathrm{day} \text { orally for patients } \\
\text { with abnormal liver enzymes (even if } \\
\text { asymptomatic) -Medication should be con- } \\
\text { tinued indefinitely throughout disease } \\
\text { course. } 3,11 \\
\text {-Initiate gradually over } 2-3 \text { weeks to full dose } \\
\text { to avoid triggering pruritus. } \\
\text { - US FDA Pregnancy Category B drug } \\
\text { - Not US FDA-approved for use in breastfeeding }\end{array}$ & $\begin{array}{l}\text { UDCA not recommended in adult PSC } \\
\text { patients } \\
\text { - Corticosteroids and other immunosuppres- } \\
\text { sants as indicated for PSC-overlap syn- } \\
\text { dromes }^{38}\end{array}$ \\
\hline Fatigue & $\begin{array}{l}\text { - Investigate alternate causes; discontinue poter } \\
\text { - Consider referral to psychological counseling ser } \\
\text { development of coping strategies }\end{array}$ & $\begin{array}{l}\text { Ily inciting medications if possible }{ }^{11} \\
\text { es for management of concomitant disorders and }\end{array}$ \\
\hline Pruritus & $\begin{array}{l}\text { Stepwise therapy, starting from first- to fourth-line } \\
\text { treatment failure, intolerance, or significant side ef } \\
\text { 1) Bile acid sequestrants such as cholestyramine c } \\
\text { to maximum dose of } 600 \mathrm{mg} / \text { day. } \\
\text { 2) Rifampicin } 150-300 \mathrm{mg} \text { orally twice daily. Star } \\
600 \mathrm{mg} / \text { day. Close monitoring of liver biochem } \\
\text { 3) Opioid antagonists such as naltrexone starting } \\
\text { 4) Sertraline starting at low doses and increasing } \\
\text {-Consider experimental treatment or referral to } \\
\text {-LT effective but should only be considered in s }\end{array}$ & $\begin{array}{l}1-4 \text {, below). Advancement to next step for } \\
\text { cts to aforementioned option: }{ }^{11,16} \\
\text { sed } 4 \mathrm{~g} \text { orally up to } 4 \text { times/day. Increase gradually } \\
\text { at } 150 \mathrm{mg} \text { daily and increase to maximum dose of } \\
\text { ries and blood counts. } \\
25 \mathrm{mg} \text { orally/day; can be increased to } 50 \mathrm{mg} / \text { day. } \\
\text { maximum of } 100 \mathrm{mg} / \text { day. } \\
\text { pecialized center for resistant cases } \\
\text { ere, refractory cases after failure of all alternatives }\end{array}$ \\
\hline $\begin{array}{l}\text { Fat-Soluble } \\
\text { Vitamin } \\
\text { Deficiency }\end{array}$ & $\begin{array}{l}\text { - Serologic laboratory monitoring of vitamins A, } \\
\text {-Yearly testing recommended if bilirubin }>2.0 \mathrm{n} \\
\text { - Enteral vitamin A, D, \& E supplementation in ca } \\
\text { malabsorption, or when diagnosed with deficier } \\
\text { - Parenteral vitamin } \mathrm{K} \text { administered empirically b } \\
\text { the setting of bleeding }\end{array}$ & $\begin{array}{l}\text { \& E (particularly in advanced disease) } \\
/ \mathrm{dL}^{3} \\
\text { es of overt cholestasis, steatorrhea and } \\
\mathrm{y}^{38} \\
\text { ore invasive procedures in overt cholestasis or in }\end{array}$ \\
\hline $\begin{array}{l}\text { Metabolic } \\
\text { Bone Disease }\end{array}$ & $\begin{array}{l}\text { - DEXA scan at PBC diagnosis with follow-up ass } \\
\text { risks and lifestyle factors }{ }^{11,16,38,115} \\
\text { Cholestasis with normal BMD: } T \text {-score }(>-1.0) \\
\text { - } \quad \text { Follow basic measures for MBD prevention or d } \\
\text {-Supplemental calcium + vitamin } \mathrm{D}_{3} \\
\text {-Regular weight-bearing exercise } \\
\text {-Abstinence from smoking } \\
\text {-Avoidance of excess alcohol intake } \\
\text {-Assessment and modification of individual risk } \\
\text { Hepatic Osteopenia: } T \text {-score }(-1.0 \text { to }-2.5) \\
\text { - DEXA scan every } 2 \text { years } \\
\text { - Follow basic preventive measures } \\
\text { - Bisphosphonate therapy may be appropriate at } \\
\text { such as prolonged glucocorticoid use } \\
\text { Hepatic Osteoporosis: T-score ( }<-2.5) \text { or history } \\
\text { - Consider other causes of low BMD } \\
\text { - Follow basic preventive measures } \\
\text { - Bisphosphonate therapy } \\
\text { - Consider HRT in postmenopausal females, pa } \\
\text { hypogonadism. Consider testosterone in male } \\
\text { - Risks and benefits of such therapies must be we } \\
\text { treatment individualized. } \\
\text { - Refer to bone specialist for management of } \\
\text { alternative therapy. } \\
\text { Interval DEXA monitoring (every } 1-3 \text { years) b } \\
\text { individual risk factors. }\end{array}$ & $\begin{array}{l}\text { sment at } 1-3 \text { year intervals based on individual } \\
\text { ayed progression: } \\
\text { actors } \\
\text { fragility fracture } \\
\text { ents with early (age }<45 \text { ) menopause or female } \\
\text { tients with hypogonadism. } \\
\text { hed, especially with regard to malignancy risks, and } \\
\text { vere or complex cases requiring consideration of } \\
\text { ed on degree of cholestasis and presence of other }\end{array}$ \\
\hline
\end{tabular}

Continued 
Marchioni Beery R.M. et al: Review of PBC \& PSC in women's health

\begin{tabular}{|c|c|c|}
\hline & Primary biliary cirrhosis (PBC) & Primary sclerosing cholangitis (PSC) \\
\hline & \multicolumn{2}{|c|}{$\begin{array}{l}\text { LT Patients }{ }^{115,191} \\
\text { - Follow basic preventive measures } \\
\text { Pre-LT: Screen with DEXA, thoracolumbar spine X-rays, free testosterone (males), 25-OH vitamin D, } \\
\text { serum calcium } \\
\text { MBD therapy for LT candidates ideally started prior to surgery and continued post-transplant given } \\
\text { rapid bone loss surrounding LT } \\
\text { Post-LT: Yearly DEXA for initial } 5 \text { years in osteopenic patients and every } 2-3 \text { years in patients with } \\
\text { normal BMD } \\
\text {-DEXA screening thereafter is determined by the presence of risk factors }\end{array}$} \\
\hline Hyperlipidemia & \multicolumn{2}{|c|}{$\begin{array}{l}\text { UDCA may provide initial step in lowering low- } \\
\text { density lipoprotein and total cholesterol levels } \\
\text { in PBC } \\
\text { - Further lipid-lowering medical therapy based on individual risks with close monitoring of liver } \\
\text { biochemical profile } \\
\text {-Large-volume plasmapheresis for management of xanthomas (particularly planar) is rarely } \\
\text { employed but may be considered in cases causing pain or limitations of manual dexterity/mobility }{ }^{166}\end{array}$} \\
\hline $\begin{array}{l}\text { Other Disease- } \\
\text { Related } \\
\text { Considerations }\end{array}$ & $\begin{array}{l}\text { Sicca Syndrome } \\
\text { - Dry eyes } \\
\text {-Artificial tears as initial management } \\
\text {-Pilocarpine or cevimeline if symptoms persist } \\
\text {-Cyclosporine ophthalmic emulsion for refrac- } \\
\text { tory cases under direction of ophthalmologist } \\
\text { - Xerostomia \& Dysphagia } \\
\text {-Saliva substitutes } \\
\text {-Pilocarpine or cevimeline if symptoms persist } \\
\text {-Encourage oral hygiene regimen (mouth-rin- } \\
\text { sing, use of fluoride-containing toothpaste, } \\
\text { dental flossing) and regular dental care } \\
\text {-Suggest salivary gland stimulation with sugar- } \\
\text { free gum or hard candy; lip care with oil or } \\
\text { petroleum-based balm/lipstick } \\
\text {-Careful swallowing (especially of pills) with } \\
\text { copious water and maintenance of upright } \\
\text { position after swallowing } \\
\text { Vaginal dryness } \\
\text {-Topical moisturizers }\end{array}$ & $\begin{array}{l}\text { Inflammatory Bowel Disease } \\
\text { - IBD treatment per standard practice guidelines } \\
\text { - Complete colonoscopy with biopsies at initial } \\
\text { PSC diagnosis } \\
\text { - Surveillance colonoscopy with biopsies per- } \\
\text { formed yearly given high risk of colorectal } \\
\text { cancer } \\
\text { - UDCA not recommended for PSC treatment or } \\
\text { for colorectal cancer chemoprevention } \\
\text { Dominant Bile Duct Strictures }{ }^{38} \\
\text { - Should be considered in the setting of clinical } \\
\text { changes, including increases in serum bilirubin } \\
\text { or ALP, cholangitis, or progressive biliary dila- } \\
\text { tion on imaging } \\
\text { ERCP should be performed for diagnostic and } \\
\text { therapeutic purposes } \\
\text { Treatment is individualized and options (con- } \\
\text { servative v. endoscopic v. surgical including LT) } \\
\text { require careful consideration } \\
\text { Recurrent Cholangitis } \\
\text { - Empiric, long-term antibiotic regimen may be } \\
\text { indicated } \\
\text { Refractory cholangitis is rarely an indication for LT }\end{array}$ \\
\hline \multirow[t]{2}{*}{$\begin{array}{l}\text { Follow-up Care } \\
\text { and Medical } \\
\text { Maintenance }\end{array}$} & $\begin{array}{l}\text { - Liver function tests every } 3-6 \text { months }{ }^{16} \\
\text { - } \quad \text { Yearly thyroid stimulating hormone level } \\
\text { - } \text { degrilial screening, particularly among first- } \\
\end{array}$ & $\begin{array}{l}\text { - } \quad \text { Liver function test monitoring } \\
\text { - } \quad \text { Malignancy screening as outlined in Table } 1\end{array}$ \\
\hline & \multicolumn{2}{|c|}{$\begin{array}{l}\text { Screening Recommendations in Cirrhosis: } \\
\text { - Variceal Screening: Upper endoscopy for initial assessment of variceal status } \\
\text {-Repeat endoscopy as determined by previous findings and standard practice guidelines }{ }^{194} \\
\text {-Management of portal hypertensive complications based on standard practice guidelines }{ }^{194} \\
\text { - Hepatocellular Carcinoma Screening: Abdominal ultrasound every } 6 \text { months }{ }^{193} \\
\text {-Serum alpha-fetoprotein measurement every } 6 \text { - } 12 \text { month can be considered }{ }^{11,16,38,193}\end{array}$} \\
\hline $\begin{array}{l}\text { Liver } \\
\text { Transplantation }\end{array}$ & $\begin{array}{l}\text { - Consideration in setting of end-stage liver } \\
\text { disease with decompensation/symptomatic } \\
\text { portal hypertension/hepatic failure }{ }^{16}\end{array}$ & $\begin{array}{l}\text { - Consideration in setting of end-stage liver } \\
\text { disease with decompensation/symptomatic } \\
\text { portal hypertension/hepatic failure; recurrent } \\
\text { or recalcitrant cholangitis }{ }^{38}\end{array}$ \\
\hline
\end{tabular}

Abbreviations: UDCA (ursodeoxycholic acid); US FDA (United States Food and Drug Administration); LT (liver transplantation); DEXA (dual-energy X-ray absorptiometry); BMD (bone mineral density); MBD (metabolic bone disease); HRT (Hormone Replacement Therapy); IBD (inflammatory bowel disease).

+including: serum alkaline phosphatase, calcium, phosphate, 25-hydroxyvitamin D, creatinine, protein electrophoresis, testosterone (males), and complete blood count; medication assessment; thoracolumbar radiography. 
Marchioni Beery R.M. et al: Review of PBC \& PSC in women's health

Table 3. Expected laboratory variants of pregnancy important in the assessment of maternal liver disease ${ }^{195}$

\begin{tabular}{ll}
\hline Laboratory tests & Proposed reason for alteration \\
\hline Elevated: & -Expected (2-4-fold) increase due to placental isoenzyme production \\
-Serum alkaline phosphatase & -Expected elevation due to placental production; can be elevated with fetal \\
-Maternal serum alpha-fetoprotein & neural tube defects \\
& -Expected mild elevation (trimesters 2 \& 3) \\
-5' Nucleotidase & -Expected elevation with pregnancy and estrogen exposure \\
-Ceruloplasmin & -Expected elevations (trimester 2 with peak at term) \\
-Serum cholesterol and triglycerides & -Expected to remain normal during pregnancy \\
Normal: & -Expected to remain normal during pregnancy \\
-Aminotransferases (AST / ALT) & -Expected to remain normal during pregnancy \\
-Serum total bile acid concentration & \\
-Prothrombin time & -Expected decrease due to relative hemodilution (of red blood cell and \\
Decreased: & hemoglobin mass) in the setting of greater plasma volume expansion \\
-Serum albumin & (particularly in trimester 2) \\
& -Expected decrease (all trimesters) \\
-Total and unconjugated bilirubin & -Expected decrease (trimesters 2 \& 3) \\
-Conjugated bilirubin* & -Expected decrease (trimesters 2 \& 3) \\
-Gamma-glutamyl transferase* &
\end{tabular}

*Abnormal (elevated) values may help to identify liver diseases in pregnancy, particularly in the setting of cholestasis.

Abbreviations: AST (aspartate aminotransferase); ALT (alanine aminotransferase).

pregnancy may be difficult, as physiologic changes associated with a normal pregnancy can mimic signs and symptoms of chronic liver disease. Therefore, it is essential to review the relevant and expected clinical variants of pregnancy (Table 3). Additionally, it must be recognized that the state of pregnancy and its associated sex-hormone burden can influence autoimmune conditions. As the interplay between pregnancy and maternal disease can affect birth outcomes and maternal course, consideration of the following topics are critical while caring for women of childbearing age with cholestatic liver disease.

Pregnancy and cholestatic liver disease

Given the anticipated elevation of ALP during pregnancy, diagnosing PBC or PSC may be challenging. The combination of history, physical examination, and investigative data are crucial. Abundant sex hormones during pregnancy can promote cholestasis, potentiating symptoms (such as pruritus and jaundice) and leading to laboratory aberrations. ${ }^{174}$ Pregnancy-associated telangiectasias $(60 \%)$, spider nevi, and palmar erythema $(50 \%)$ can mimic signs of chronic liver disease. ${ }^{175}$ Hepatomegaly, splenomegaly, and jaundice are abnormal in pregnancy and warrant investigation. ${ }^{176}$ Hepatic accumulation of cholesterol and triglycerides coupled with gallbladder enlargement and cholesterol supersaturation predispose to gallstone formation and related effects. ${ }^{177}$ Elevations in serum aminotransferases, bilirubin, and total bile acid levels may provide diagnostic aid. If necessary, MRCP may be carried out in the second or third trimesters with reluctance to perform in the first. ERCP is reserved for cases requiring anticipated endoscopic intervention. Clinical vigilance is paramount, as both maternal and fetal morbidity and mortality are increased in the setting of pregnancy and liver disease. Please see Table 4 describing the overlap features and clinical intricacies of pregnancy and liver disease.

Pregnant patients with chronic liver diseases including PBC and PSC should be followed by a high-risk obstetrician and hepatologist for careful monitoring and frequent reassessments throughout pregnancy and delivery. Drug therapy during pregnancy should follow US Food and Drug Administration (US FDA) safety guidelines (Table 5) and should be focused on relieving intolerable symptoms (such as pruritus) that can occur or worsen with pregnancy. ${ }^{175}$ Persistent symptoms and lab abnormalities in the postpartum period warrant further investigation.

Cirrhosis is not a contraindication to pregnancy in wellcompensated disease states without portal hypertension. However, pregnancy in women with cirrhosis is rare due to hypothalamic-pituitary abnormalities yielding perturbations in estrogen and endocrine metabolism. Although maternal and fetal outcomes are variable, prognosis is generally most favorable for patients with well-compensated liver disease. Pregnancy in the setting of cirrhosis has been associated with increased rates of spontaneous abortions, premature births, and perinatal deaths. ${ }^{175}$

Portal pressure may worsen due to a variety of factors associated with pregnancy, including increased intravascular blood volume, increased vascular resistance, and compression of the inferior vena cava by the gravid uterus. This may predispose patients to such complications as variceal hemorrhage, portosystemic encephalopathy, and hepatic failure. ${ }^{175}$ Variceal bleeding risk is particularly pronounced during the second trimester at the time of peak portal pressures and during delivery in association with straining and fetal expulsion. ${ }^{174}$ Thus, all pregnant patients with cirrhosis should undergo endoscopic assessment for 
Table 4. Pregnancy-related clinical manifestations with shared features of liver disease

\begin{tabular}{|c|c|}
\hline Clinical sign/symptom & Potential etiologies/differential diagnostic considerations ${ }^{195}$ \\
\hline Telangiectasias \& Spider nevi & - Normal due to presence of increased estrogen \\
\hline Pruritus & $\begin{array}{l}\text { Dermatologic: }{ }^{196,197} \\
\text {-Atopic eruption of pregnancy (including eczema in pregnancy, prurigo of } \\
\text { pregnancy, and pruritic folliculitis of pregnancy). Typically manifests early in } \\
\text { pregnancy, }<3^{\text {rd }} \text { trimester with trunk and limb skin involvement. } \\
\text {-Polymorphic eruption of pregnancy (also known as pruritic urticarial papules and } \\
\text { plaques of pregnancy); pemphigoid gestationis. Typically manifests in } 3^{\text {rd }} \text { trimester } \\
\text { with predominant abdominal skin involvement. Pemphigoid gestationis may be } \\
\text { associated with small for date infant, while the other dermatologic conditions are } \\
\text { usually without significant maternal or fetal risks. } \\
\text { Gastrointestinal: } \\
\text {-Intrahepatic cholestasis of pregnancy. Generally presents as sudden onset of } \\
\text { generalized pruritus during late } 2^{\text {nd }} \text { or } 3^{\text {rd }} \text { trimester. Typically without rash but may } \\
\text { have secondary skin lesions such as linear skin excoriations and excoriated papules } \\
\text { resulting from scratching. Associated with elevated total serum bile acid levels and } \\
\text { fetal risks including still births, prematurity, and fetal distress. } \\
\text { Endocrine: } \\
\text {-Sex-hormone abundance during pregnancy }\end{array}$ \\
\hline Fatigue & $\begin{array}{l}\text { May have multifactorial etiology including: } \\
\text { - Endocrine: Thyroid disorder, gestational diabetes } \\
\text { - Hematologic: Anemia } \\
\text { - Cardiovascular: Hypotension (i.e. inferior vena cava compression by gravid uterus); } \\
\text { hypovolemia/dehydration; hypertension (i.e. preeclampsia); cardiomyopathy } \\
\text { - Musculoskeletal: Physical and mechanical stress of gravid uterus. Lumbar } \\
\text { hyperextension resulting in low back pain; joint laxity resulting from pregnancy } \\
\text { hormones (progesterone/relaxin) and leading to pelvic pain (pubic symphysis } \\
\text { change/diastasis); excess weight-bearing and bone alterations leading to joint pain } \\
\text { (low back, knees, sacroiliac joints) } \\
\text { - Psychiatric: Disturbed sleep, depression } \\
\text { - Other: Medication-induced effects }\end{array}$ \\
\hline Abdominal pain & $\begin{array}{l}\text { - Gastrointestinal: Gallstone disease, cholangitis, gastroesophageal reflux disease, } \\
\text { constipation, irritable bowel syndrome, appendicitis, diverticulitis, intra-abdom- } \\
\text { inal hemorrhage } \\
\text { Obstetric/Gynecologic: Ectopic pregnancy (early), spontaneous or threatened } \\
\text { abortion, labor (preterm or term), leiomyomas, endometriosis, ovarian cyst, } \\
\text { pelvic inflammatory disease/salpingitis, uterine rupture } \\
\text { - Genitourinary: Urinary tract infection, cystitis, pyelonephritis, nephrolithiasis }\end{array}$ \\
\hline Jaundice & $\begin{array}{l}\text { - Gastrointestinal: Obstructive gallstone disease/cholangitis; drug-induced cholestasis } \\
\text { - } \quad \text { Obstetric: HELLP syndrome (hemolysis, elevated liver enzymes, low platelets) } \\
\text { - Hematologic: Hemolysis }\end{array}$ \\
\hline
\end{tabular}

esophageal varices in the second trimester. If large varices are seen, pharmacologic therapy with a non-selective betablocker is indicated (Table 5). Acute variceal hemorrhage is largely managed endoscopically during pregnancy. Vaginal delivery with an assisted, short second stage of labor is preferred to abdominal surgery, although caesarean section is recommended in patients with large varices to avoid delivery-associated increases in portal pressure and risk of variceal hemorrhage.

Up to $1 / 4$ of patients diagnosed with PBC are of reproductive age. ${ }^{178}$ Although several patients maintain stable liver biochemistries throughout pregnancy, most experience a post-partum disease flare independent of preconception or gestational disease activity. ${ }^{178,179}$ Pruritus is variably reported (3-49\%) and may be influenced by histologic stage of the underlying liver disease. ${ }^{178-180}$ The demonstrated remission of PBC in pregnancy may be due to an autoimmune shift from predominantly cell-mediated to humoral immunity. Additionally, steroid hormone levels (including estrogen, progesterone, and corticosteroids) that elevate dramatically in pregnancy inhibit T-cell activation and nuclear-factor-kB activity. The T-helper (Th)-1/ Th- 2 balance is shifted toward a Th-2 response in pregnancy, and post-partum reversal of this cytokine balance may reflect the observed disease flare. Adverse fetal events do not appear to be associated with biochemical disease activity during preconception or pregnancy periods. ${ }^{178}$ 
Marchioni Beery R.M. et al: Review of PBC \& PSC in women's health

Table 5. Primary biliary cirrhosis and primary sclerosing cholangitis in pregnancy: medication safety considerations

\begin{tabular}{|c|c|c|}
\hline US FDA category & Definition & Medications \\
\hline$A$ & $\begin{array}{l}\text { Controlled studies in pregnant women fail to demonstrate fetal risk in the } \\
\text { first trimester, or animal reproduction studies fail to demonstrate fetal } \\
\text { risk. Possibility of fetal harm appears remote. }\end{array}$ & \\
\hline B & $\begin{array}{l}\text { Animal studies do not indicate fetal risk and there are no adequate well- } \\
\text { controlled studies in pregnant women, or animal studies have demon- } \\
\text { strated adverse effect but controlled studies in pregnant women have } \\
\text { failed to demonstrate risk. Possibility of fetal harm appears remote, but } \\
\text { drug should only be used in pregnancy if clearly indicated. }\end{array}$ & $\begin{array}{l}\text { - Ursodeoxycholic } \\
\text { Acid } \\
\text { - Octreotide } \\
\text { - Vasopressin }\end{array}$ \\
\hline C & $\begin{array}{l}\text { Animal reproduction studies indicate fetal risk, and there are no } \\
\text { adequate well-controlled studies in pregnant women. Benefit of } \\
\text { medication may be acceptable despite potential risk. Drug should only } \\
\text { be used in pregnancy if clearly indicated. }\end{array}$ & - Propranolol \\
\hline D & $\begin{array}{l}\text { Evidence of fetal risk exists based on data from human studies or from } \\
\text { investigational/marketing data recorded in humans. Medication benefit } \\
\text { may be acceptable despite risk. Drug should only be used in pregnancy if } \\
\text { clearly indicated. }\end{array}$ & \\
\hline$x$ & $\begin{array}{l}\text { Definite fetal risk based on animal or human studies or based on human } \\
\text { experience. Medication risk clearly outweighs any possible benefit. Drug } \\
\text { is contraindicated in pregnancy. }\end{array}$ & \\
\hline
\end{tabular}

Abbreviation: US FDA (United States Food and Drug Administration).

Reference: http://www.regulations.gov/\#! documentDetail;D=FDA-2006-N-0515

Maternal disease and birth outcomes

A retrospective case study and literature review (1950-2014) identified 98 pregnancies in 72 PBC patients (64\% of whom were diagnosed preconception). Live births were reported in $65 \%$, along with 24 miscarriages and three documented stillbirths. One baby was born with a chromosomal abnormality; minor birth defects were not recorded. There were no maternal deaths, and serious disease progression was rarely reported ( $n=2$; one patient requiring LT and one intensive care). ${ }^{179}$

A retrospective study (1987-2012) of 223 consecutive patients with PBC found that a significantly lower number of patients $(n=186,79.8 \%)$ became pregnant compared to controls $(n=367)$. Most pregnancies $(499 / 507)$ were determined prior to PBC diagnosis. No significant differences in miscarriages or preterm deliveries were seen. No congenital abnormalities were reported. The risks of perinatal death $(n=3)$ and childbirth complications $(1.2 \%, n=6$; five cases of placenta previa and one case of fetal distress) were significantly greater in PBC cases compared to controls. (The overall prevalence of placenta previa is estimated at $5.2 / 1000$ pregnancies, although variations may exist by world region. ${ }^{181}$ ) Interestingly, eight pregnancies in six women occurring after PBC diagnosis had favorable maternal and fetal outcomes.

Although stable maternal disease activity without fetal loss has been reported in PSC, ${ }^{182,183}$ maternal PSC has also been linked to increased risks of preterm birth and cesarean section delivery. ${ }^{184}$ No association has been identified between maternal PSC and risk of congenital abnormalities, stillbirths, small for gestational age infants, or neonatal deaths. ${ }^{184}$

\section{UDCA and pregnancy outcomes}

High maternal serum bile acid levels have been linked with an increased probability of adverse fetal events (such as spontaneous preterm delivery, asphyxial events, and meconium staining) in patients with severe intrahepatic cholestasis of pregnancy (ICP) and bile acid levels $\geqslant 40 \mu \mathrm{mol} / \mathrm{L}$, whereas no increased fetal risks were detected with lower levels. ${ }^{185}$ UDCA treatment appears to lower maternal serum bile acid levels, reduce passage to the fetus, and decrease bile acid levels in colostrum. ${ }^{186}$ UDCA has also been shown to prevent sex-hormone induced cholestasis and improve impaired progesterone metabolism in ICP patients. ${ }^{187}$

UDCA is generally continued throughout most of pregnancy and breastfeeding. ${ }^{188,189}$ A Cochrane Review (21 randomized controlled trials, 1197 ICP patients) found that UDCA improved pruritus over placebo in a majority of included trials. ${ }^{190}$ No significant differences in fetal distress and spontaneous preterm births were reported in UDCAtreated versus placebo groups. Less preterm deliveries were observed in UDCA-treated patients. There were no significant differences in rates of meconium passage, caesarean section deliveries, or neonatal intensive care unit admissions between treated and untreated patients. ${ }^{190}$ Limited data exist (particularly during the first trimester and breastfeeding periods), and it is unclear whether extracted data from ICP cases could be applied to PBC and PSC. ${ }^{38}$ Significant teratogenic effects linked with UDCA, however, have not been observed in humans to date. ${ }^{179,180,188}$

\section{Conclusions}

PBC and PSC are two major types of chronic cholestatic liver disease. Although there exist some shared characteristics, 
each disorder also bears several distinguishing features. A comprehensive overview of PBC and PSC has been provided with an emphasis on commonly encountered clinical manifestations and a focus on the female patient. Selected women's health topics including metabolic bone disease, hyperlipidemia and cardiovascular risk, and pregnancy-related matters pertaining to maternal disease and birth outcomes have been discussed. This thorough review of PBC and PSC has addressed unique clinical considerations applicable to the care of female patients with cholestatic liver disease.

\section{Conflict of interest}

None

\section{Author contributions}

Acquisition of information and composition of the manuscript (RMMB), revising the manuscript (HV), acquisition and description of the histologic figures (FF).

\section{References}

[1] Karlsen TH, Vesterhus M, Boberg KM. Controversies in the management of primary biliary cirrhosis and primary sclerosing cholangitis. Aliment Pharmacol Ther 2014;39:282-301. doi: 10.1111/apt.12581.

[2] Boonstra K, Beuers U, Ponsioen CY. Epidemiology of primary sclerosing cholangitis and primary biliary cirrhosis: a systematic review. J Hepatol 2012;56:1181-1188. doi: 10.1016/j.jhep.2011.10.025.

[3] Lindor KD, Gershwin ME, Poupon R, Kaplan M, Bergasa NV, Heathcote EJ, et al. Primary biliary cirrhosis. Hepatology 2009;50:291-308. doi: 10.1002/hep.22906.

[4] Kaplan MM, Gershwin ME. Primary biliary cirrhosis. N Engl J Med 2005;353: 1261-1273. doi: 10.1056/NEJMra043898.

[5] Bowlus CL, Gershwin ME. The diagnosis of primary biliary cirrhosis. Autoimmun Rev 2014;13:441-444. doi: 10.1016/j.autrev.2014.01.041.

[6] Gershwin ME, Selmi C, Worman HJ, Gold EB, Watnik M, Utts J, et al. Risk factors and comorbidities in primary biliary cirrhosis: a controlled interviewbased study of 1032 patients. Hepatology 2005;42:1194-1202. doi: 10.1002/hep.20907.

[7] Parikh-Patel A, Gold EB, Worman H, Krivy KE, Gershwin ME. Risk factors for primary biliary cirrhosis in a cohort of patients from the United States. Hepatology 2001;33:16-21. doi: 10.1053/jhep.2001.21165.

[8] Momah N, Lindor KD. Primary biliary cirrhosis in adults. Expert Rev Gastroenterol Hepatol 2014;8:427-433. doi: 10.1586/17474124.2014. 888950.

[9] Parikh-Patel A, Gold E, Utts J, Gershwin ME. The association between gravidity and primary biliary cirrhosis. Ann Epidemiol 2002;12:264-272. doi: 10.1016/S1047-2797(01)00277-0.

[10] Boonstra K, Kunst $A E$, Stadhouders $P H$, Tuynman $H A$, Poen $A C$, van Nieuwkerk KM, et al. Rising incidence and prevalence of primary biliary cirrhosis: a large population-based study. Liver Int 2014;34:e31-e38. doi: 10.1111/liv.12434.

[11] European Association for the Study of the Liver. EASL Clinical Practice Guidelines: management of cholestatic liver diseases. J Hepatol 2009;51: 237-267. doi: 10.1016/j.jhep.2009.04.009.

[12] Gotthardt D, Runz H, Keitel V, Fischer C, Flechtenmacher C, Wirtenberger M, et al. A mutation in the canalicular phospholipid transporter gene, ABCB4, is associated with cholestasis, ductopenia, and cirrhosis in adults. Hepatology 2008;48:1157-1166. doi: 10.1002/hep.22485.

[13] Kuiper EM, Zondervan PE, van Buuren HR. Paris criteria are effective in diagnosis of primary biliary cirrhosis and autoimmune hepatitis overlap syndrome. Clin Gastroenterol Hepatol 2010;8:530-534. doi: 10.1016/ j.cgh.2010.03.004.

[14] Prince M, Chetwynd A, Newman W, Metcalf JV, James OF. Survival and symptom progression in a geographically based cohort of patients with primary biliary cirrhosis: follow-up for up to 28 years. Gastroenterology 2002;123:1044-1051. doi: 10.1053/gast.2002.36027.

[15] Springer J, Cauch-Dudek K, O'Rourke K, Wanless IR, Heathcote EJ. Asymptomatic primary biliary cirrhosis: a study of its natural history and prognosis. Am J Gastroenterol 1999;94:47-53.
[16] Lindor KD, Gershwin ME, Poupon R, Kaplan M, Bergasa NV, Heathcote E], et al. Primary biliary cirrhosis. Hepatology 2009;50:291-308. doi: 10.1002/hep.22906.

[17] Corpechot C, Carrat F, Bonnand AM, Poupon RE, Poupon R. The effect of ursodeoxycholic acid therapy on liver fibrosis progression in primary biliary cirrhosis. Hepatology 2000;32:1196-1199. doi: 10.1053/jhep.2000.20240.

[18] Rudic JS, Poropat G, Krstic MN, Bjelakovic G, Gluud C. Ursodeoxycholic acid for primary biliary cirrhosis. Cochrane Database Syst Rev 2012;12: CD000551. doi: 10.1002/14651858.CD000551.

[19] Degott C, Zafrani ES, Callard P, Balkau B, Poupon RE, Poupon R. Histopathological study of primary biliary cirrhosis and the effect of ursodeoxycholic acid treatment on histology progression. Hepatology 1999;29:1007-1012. doi: 10.1002/hep.510290444.

[20] Quarneti C, Muratori P, Lalanne C, Fabbri A, Menichella R, Granito A, et al. Fatigue and pruritus at onset identify a more aggressive subset of primary biliary cirrhosis. Liver Int 2014. doi: 10.1111/liv.12560.

[21] Lindor KD, Jorgensen RA, Therneau TM, Malinchoc M, Dickson ER Ursodeoxycholic acid delays the onset of esophageal varices in primary biliary cirrhosis. Mayo Clin Proc 1997;72:1137-1140. doi: 10.4065/ 72.12.1137.

[22] Poupon RE, Lindor KD, Cauch-Dudek K, Dickson ER, Poupon R, Heathcote EJ. Combined analysis of randomized controlled trials of ursodeoxycholic acid in primary biliary cirrhosis. Gastroenterology $1997 ; 113: 884-890$. doi: 10.1016/S0016-5085(97)70183-5.

[23] Poropat G, Giljaca V, Stimac D, Gluud C. Bile acids for liver-transplanted patients. Cochrane Database Syst Rev 2010;(17):CD005442. doi: 10.1002/ 14651858.CD005442.

[24] Angulo P, Dickson ER, Therneau TM, Jorgensen RA, Smith C, DeSotel CK, et al. Comparison of three doses of ursodeoxycholic acid in the treatment of primary biliary cirrhosis: a randomized trial. J Hepatol 1999;30:830-835. doi: 10.1016/S0168-8278(99)80136-6.

[25] Pares A, Caballeria L, Rodes J. Excellent long-term survival in patients with primary biliary cirrhosis and biochemical response to ursodeoxycholic acid. Gastroenterology 2006;130:715-720. doi: 10.1053/j.gastro.2005. 12.029 .

[26] Corpechot C, Abenavoli L, Rabahi N, Chretien Y, Andreani T, Johanet C, et al. Biochemical response to ursodeoxycholic acid and long-term prognosis in primary biliary cirrhosis. Hepatology 2008;48:871-877. doi: 10.1002/ hep. 22428.

[27] Corpechot C, Chazouillres O, Poupon R. Early primary biliary cirrhosis: biochemical response to treatment and prediction of long-term outcome. J Hepatol 2011;55:1361-1367. doi: 10.1016/j.jhep.2011.02.031.

[28] Kumagi T, Guindi M, Fischer SE, Arenovich T, Abdalian R, Coltescu C, et al. Baseline ductopenia and treatment response predict long-term histological progression in primary biliary cirrhosis. Am J Gastroenterol 2010;105: 2186-2194.

[29] Kuiper EM, Hansen BE, de Vries RA, den Ouden-Muller JW, van Ditzhuijsen $\mathrm{TJ}$, Haagsma EB, et al. Improved prognosis of patients with primary biliary cirrhosis that have a biochemical response to ursodeoxycholic acid. Gastroenterology 2009;136:1281-1287. doi: 10.1053/j.gastro.2009. 01.003.

[30] Momah N, Silveira MG, Jorgensen R, Sinakos E, Lindor KD. Optimizing biochemical markers as endpoints for clinical trials in primary biliary cirrhosis. Liver Int 2012;32:790-795. doi: 10.1111/j.1478-3231.2011.02678.x.

[31] Shi TY, Zhang LN, Chen H, Wang L, Shen M, Zhang X, et al. Risk factors for hepatic decompensation in patients with primary biliary cirrhosis. World J Gastroenterol 2013;19:1111-1118.

[32] Poupon RE, Bonnand AM, Chretien Y, Poupon R. Ten-year survival in ursodeoxycholic acid-treated patients with primary biliary cirrhosis. The UDCA-PBC Study Group. Hepatology 1999;29:1668-1671. doi: 10.1002/ hep. 510290603.

[33] Floreani A, Caroli D, Variola A, Rizzotto ER, Antoniazzi S, Chiaramonte M, et al. A 35-year follow-up of a large cohort of patients with primary biliary cirrhosis seen at a single centre. Liver Int 2011;31:361-368. doi: 10.1111/ j.1478-3231.2010.02366.x.

[34] ter Borg PC, Schalm SW, Hansen BE, van Buuren HR, Dutch PBC Study Group. Prognosis of ursodeoxycholic acid-treated patients with primary biliary cirrhosis. Results of a 10-yr cohort study involving 297 patients. Am J Gastroenterol 2006;101:2044-2050.

[35] Lee YM, Kaplan MM. The natural history of PBC: has it changed? Semin Liver Dis 2005;25:321-326. doi: 10.1055/s-2005-916323.

[36] Bonnand AM, Heathcote EJ, Lindor KD, Poupon RE. Clinical significance of serum bilirubin levels under ursodeoxycholic acid therapy in patients with primary biliary cirrhosis. Hepatology 1999;29:39-43. doi: 10.1002/ hep. 510290140 .

[37] Lee J, Belanger A, Doucette JT, Stanca C, Friedman S, Bach N. Transplantation trends in primary biliary cirrhosis. Clin Gastroenterol Hepatol 2007;5:1313-1315. doi: 10.1016/j.cgh.2007.07.015. 
[38] Chapman R, Fevery J, Kalloo A, Nagorney DM, Boberg KM, Shneider B, et al. Diagnosis and management of primary sclerosing cholangitis. Hepatology 2010;51:660-678. doi: 10.1002/hep.23294.

[39] Lee YM, Kaplan MM. Primary sclerosing cholangitis. N Engl J Med 1995;332: 924-933, doi: 10.1056/NEJM199504063321406.

[40] Bambha K, Kim WR, Talwalkar J, Torgerson H, Benson JT, Therneau TM, et al. Incidence, clinical spectrum, and outcomes of primary sclerosing cholangitis in a United States community. Gastroenterology 2003;125: 1364-1369. doi: 10.1016/j.gastro.2003.07.011.

[41] Cassinotti A, Birindelli S, Clerici M, Trabattoni D, Lazzaroni M, Ardizzone S, et al. HLA and autoimmune digestive disease: a clinically oriented review for gastroenterologists. Am J Gastroenterol 2009;104:195-217.

[42] Folseraas T, Liaskou E, Anderson CA, Karlsen TH. Genetics in PSC: what do the "risk genes" teach us? Clin Rev Allergy Immunol 2014. doi: 10.1038/ ajg.2008.10.

[43] Chapman RW, Varghese Z, Gaul R, Patel G, Kokinon N, Sherlock S. Association of primary sclerosing cholangitis with HLA-B8. Gut $1983 ; 24$ : 38-41. doi: 10.1136/gut.24.1.38.

[44] Wiencke K, Karlsen TH, Boberg KM, Thorsby E, Schrumpf E, Lie BA, et al. Primary sclerosing cholangitis is associated with extended HLA-DR3 and HLA-DR6 haplotypes. Tissue Antigens 2007;69:161-169. doi: 10.1111/ j.1399-0039.2006.00738.x.

[45] Mehal WZ, Lo Y-D, Wordsworth BP, Neuberger JM, Hubscher SC, Fleming $\mathrm{KA}$, et al. HLA DR4 is a marker for rapid disease progression in primary sclerosing cholangitis. Gastroenterology 1994;106:160-167.

[46] Prochazka EJ, Terasaki PI, Park MS, Goldstein LI, Busuttil RW. Association of primary sclerosing cholangitis with HLA-DRw52a. N Engl J Med 1990;322: 1842-1844. doi: 10.1056/NEJM199006283222603.

[47] Spurkland A, Saarinen S, Boberg KM, Mitchell S, Broome U, Caballeria L, et al. HLA class II haplotypes in primary sclerosing cholangitis patients from five European populations. Tissue Antigens 1999;53:459-469. doi: 10.1034/j.1399-0039.1999.530502.x

[48] van Milligen de Wit AW, van Deventer SJ, Tytgat GN. Immunogenetic aspects of primary sclerosing cholangitis: implications for therapeutic strategies. Am J Gastroenterol 1995;90:893-900.

[49] Saarinen S, Olerup O, Broomé U. Increased frequency of autoimmune diseases in patients with primary sclerosing cholangitis. Am J Gastroenterol 2000;95:3195-3199.

[50] Loftus EV Jr, Sandborn WJ, Tremaine WJ, Mahoney DW, Zinsmeister AR, Offord KP, et al. Primary sclerosing cholangitis is associated with nonsmoking: a case-control study. Gastroenterology 1996;110:1496-1502. doi: 10.1053/gast.1996.v110.pm8613055

[51] Mitchell SA, Thyssen M, Orchard TR, Jewell DP, Fleming KA, Chapman RW. Cigarette smoking, appendectomy, and tonsillectomy as risk factors for the development of primary sclerosing cholangitis: a case control study. Gut 2002;51:567-573. doi: 10.1136/gut.51.4.567.

[52] Hirschfield GM, Karlsen TH, Lindor KD, Adams DH. Primary sclerosing cholangitis. The Lancet 2013;382:1587-1599. doi: 10.1016/S01406736(13)60096-3.

[53] Andersen IM, Tengesdal G, Lie BA, Boberg KM, Karlsen TH, Hov JR. Effects of coffee consumption, smoking, and hormones on risk for primary sclerosing cholangitis. Clin Gastroenterol Hepatol 2014;12:1019-1028. doi: 10.1016/j.cgh.2013.09.024.

[54] Quinton JF, Sendid B, Reumaux D, Duthilleul P, Cortot A, Grandbastien B, et al. Anti-Saccharomyces cerevisiae mannan antibodies combined with antineutrophil cytoplasmic autoantibodies in inflammatory bowel disease: prevalence and diagnostic role. Gut 1998;42:788-791. doi: 10.1136/ gut.42.6.788.

[55] Terjung B, Worman HJ. Anti-neutrophil antibodies in primary sclerosing cholangitis. Best Pract Res Clin Gastroenterol 2001;15:629-642. doi: 10.1053/bega.2001.0209.

[56] Schulte-Pelkum J, Radice A, Norman GL, Lomicronpez Hoyos M, Lakos G, Buchner $\mathrm{C}$, et al. Novel clinical and diagnostic aspects of antineutrophil cytoplasmic antibodies. J Immunol Res 2014;2014:185416. doi: 10.1155/ 2014/185416.

[57] Plevy S. Do serological markers and cytokines determine the indeterminate? J Clin Gastroenterol 2004;38:S51-6. doi: 10.1097/01.mcg. $0000124026.92823 . \mathrm{fc}$

[58] Oudkerk Pool M, Ellerbroek PM, Ridwan BU, Goldschmeding R, von Blomberg BM, Pena AS, et al. Serum antineutrophil cytoplasmic autoantibodies in inflammatory bowel disease are mainly associated with ulcerative colitis. A correlation study between perinuclear antineutrophi cytoplasmic autoantibodies and clinical parameters, medical, and surgical treatment. Gut 1993;34:46-50. doi: 10.1136/gut.34.1.46.

[59] Bansi DS, Fleming KA, Chapman RW. Importance of antineutrophil cytoplasmic antibodies in primary sclerosing cholangitis and ulcerative colitis: prevalence, titre, and IgG subclass. Gut 1996;38:384-389. doi: 10.1136/gut.38.3.384.

[60] Ellerbroek PM, Oudkerk Pool M, Ridwan BU, Dolman KM, von Blomberg BM, von dem Borne $A E$, et al. Neutrophil cytoplasmic antibodies ( $p-A N C A$ ) in ulcerative colitis. J Clin Pathol 1994;47:257-262. doi: 10.1136/ jcp.47.3.257.

[61] Hov JR, Boberg KM, Karlsen TH. Autoantibodies in primary sclerosing cholangitis. World J Gastroenterol 2008;14:3781-3791. doi: 10.3748/ wjg.14.3781.

[62] Bodenheimer JC Jr, LaRusso NF, Thayer WR Jr, Charland C, Staples PJ, Ludwig J. Elevated circulating immune complexes in primary sclerosing cholangitis. Hepatology 1983;3:150-154. doi: 10.1002/hep.1840030203.

[63] Saich R, Chapman R. Primary sclerosing cholangitis, autoimmune hepatitis and overlap syndromes in inflammatory bowel disease. World J Gastroenterol 2008; $14: 331-337$

[64] Bergquist A, Lindberg G, Saarinen S, Broomé U. Increased prevalence of primary sclerosing cholangitis among first-degree relatives. J Hepatol 2005;42:252-256. doi: 10.1016/j.jhep.2004.10.011.

[65] Bergquist A, Montgomery SM, Bahmanyar S, Olsson R, Danielsson \&, Lindgren $\mathrm{S}$, et al. Increased risk of primary sclerosing cholangitis and ulcerative colitis in first-degree relatives of patients with primary sclerosing cholangitis. Clin Gastroenterol Hepatol 2008;6:939-943. doi: 10.1016/j.cgh.2008.03.016.

[66] Seibold F, Slametschka D, Gregor M, Weber P. Neutrophil autoantibodies: a genetic marker in primary sclerosing cholangitis and ulcerative colitis. Gastroenterology 1994;107:532-536.

[67] Loftus EV Jr, Harewood GC, Loftus CG, Tremaine WJ, Harmsen WS, Zinsmeister AR, et al. PSC-IBD: a unique form of inflammatory bowel disease associated with primary sclerosing cholangitis. Gut 2005;54:9196. doi: 10.1136/gut.2004.046615.

[68] Yimam KK, Bowlus CL. Diagnosis and classification of primary sclerosing cholangitis. Autoimmun Rev 2014;13:445-450. doi: 10.1016/ j.autrev.2014.01.040

[69] Broomé U, Bergquist A. Primary sclerosing cholangitis, inflammatory bowel disease, and colon cancer. Semin Liver Dis 2006;26:31-41. doi: 10.1055/ s-2006-933561.

[70] Bernstein CN, Blanchard JF, Rawsthorne P, Yu N. The prevalence of extraintestinal diseases in inflammatory bowel disease: a population-based study. Am J Gastroenterol 2001;96:1116-1122. doi: 10.1111/j.1572-0241.

[71] Claessen MM, Vleggaar FP, Tytgat KM, Siersema PD, van Buuren HR. High lifetime risk of cancer in primary sclerosing cholangitis. J Hepatol 2009;50: 158-164. doi: 10.1016/j.jhep.2008.08.013.

[72] Lundqvist K, Broomé U. Differences in colonic disease activity in patients with ulcerative colitis with and without primary sclerosing cholangitis: a case control study. Dis Colon Rectum 1997;40:451-456. doi: 10.1007/BF02258391.

[73] Verdonk RC, Dijkstra G, Haagsma EB, Shostrom VK, Van den Berg AP, Kleibeuker $\mathrm{JH}$, et al. Inflammatory bowel disease after liver transplantation: risk factors for recurrence and de novo disease. Am J Transplant 2006;6: 1422-1429. doi: 10.1111/j.1600-6143.2006.01333.x.

[74] Sinakos E, Samuel S, Enders F, Loftus EV Jr, Sandborn WJ, Lindor KD. Inflammatory bowel disease in primary sclerosing cholangitis: a robust yet changing relationship. Inflamm Bowel Dis 2013:19:1004-1009. doi: 10.1097/MIB.0b013e3182802893.

[75] Eaton JE, Talwalkar JA, Lazaridis KN, Gores G], Lindor KD. Pathogenesis of primary sclerosing cholangitis and advances in diagnosis and management. Gastroenterology 2013:145:521-536. doi: 10.1053/j.gastro.2013.06.052.

[76] Bangarulingam SY, Gossard AA, Petersen BT, Ott BJ, Lindor KD. Complications of endoscopic retrograde cholangiopancreatography in primary sclerosing cholangitis. Am J Gastroenterol 2009;104:855-860. doi: 10.1038/ajg.2008.161.

[77] Abdalian R, Heathcote EJ. Sclerosing cholangitis: a focus on secondary causes. Hepatology 2006;44:1063-1074. doi: 10.1002/hep.21405.

[78] Angulo $P$, Maor-Kendler $Y$, Lindor KD. Small-duct primary sclerosing cholangitis: a long-term follow-up study. Hepatology 2002;35:14941500. doi: 10.1053/jhep.2002.33202.

[79] Boonstra K, Weersma RK, van Erpecum KJ, Rauws EA, Spanier BW, Poen AC, et al. Population-based epidemiology, malignancy risk, and outcome of primary sclerosing cholangitis. Hepatology 2013;58:2045-2055. doi: 10.1002/ hep. 26565 .

[80] Broomé U, Glaumann H, Lindstom E, Loof L, Almer S, Prytz H, et al. Natural history and outcome in 32 Swedish patients with small duct primary sclerosing cholangitis (PSC). J Hepatol 2002;36:586-589. doi: 10.1016/ S0168-8278(02)00036-3.

[81] Floreani A, Rizzotto ER, Ferrara F, Carderi I, Caroli D, Blasone L, et al. Clinical course and outcome of autoimmune hepatitis/primary sclerosing cholangitis overlap syndrome. Am J Gastroenterol 2005;100:1516-1522. doi: $10.1111 / j .1572-0241.2005 .41841 . x$

[82] Boberg KM, Fausa O, Haaland T, Holter E, Mellbye OJ, Spurkland A, et al. Features of autoimmune hepatitis in primary sclerosing cholangitis: an evaluation of 114 primary sclerosing cholangitis patients according to a scoring system for the diagnosis of autoimmune hepatitis. Hepatology 1996;23:1369-1376. doi: 10.1002/hep.510230612.

[83] Trivedi PJ, Chapman RW. PSC, AIH and overlap syndrome in inflammatory bowel disease. Clinics and Research in Hepatology and Gastroenterology 2012;36:420-436. doi: 10.1016/j.clinre.2011.10.007 
[84] Ota $M$, Katsuyama $Y$, Hamano $H$, Umemura $T$, Kimura A, Yoshizawa $\mathrm{K}$, et al. Two critical genes (HLA-DRB1 and ABCF1) in the HLA region are associated with the susceptibility to autoimmune pancreatitis. Immunogenetics 2007; 59:45-52. doi: 10.1007/s00251-006-0178-2.

[85] Ghazale A, Chari ST, Zhang L, Smyrk TC, Takahashi N, Levy MJ, et al. Immunoglobulin G4-associated cholangitis: clinical profile and response to therapy. Gastroenterology 2008;134:706-715. doi: 10.1053/j.gastro. 2007.12.009.

[86] Porayko MK, Wiesner RH, LaRusso NF, Ludwig J, MacCarty RL, Steiner BL, et al. Patients with asymptomatic primary sclerosing cholangitis frequently have progressive disease. Gastroenterology 1990;98:1594-1602.

[87] Ponsioen CY, Vrouenraets SM, Prawirodirdjo W, Rajaram R, Rauws EA, Mulder $\mathrm{CJ}$, et al. Natural history of primary sclerosing cholangitis and prognostic value of cholangiography in a Dutch population. Gut 2002;51: 562-566. doi: 10.1136/gut.51.4.562.

[88] Gautam M, Cheruvattath R, Balan V. Recurrence of autoimmune liver disease after liver transplantation: a systematic review. Liver Transpl 2006; 12:1813-1824. doi: 10.1002/It.20910.

[89] Campsen J, Zimmerman MA, Trotter JF, Wachs M, Bak T, Steinberg T, et al. Clinically recurrent primary sclerosing cholangitis following liver transplantation: a time course. Liver Transpl 2008;14:181-185. doi: 10.1002/ It. 21313

[90] Triantos CK, Koukias NM, Nikolopoulou VN, Burroughs AK. Meta-analysis: ursodeoxycholic acid for primary sclerosing cholangitis. Aliment Pharmacol Ther 2011;34:901-910. doi: 10.1111/j.1365-2036.2011.04822.x.

[91] Lindor KD, Kowdley KV, Luketic VA, Harrison ME, McCashland T, Befeler AS, et al. High-dose ursodeoxycholic acid for the treatment of primary sclerosing cholangitis. Hepatology 2009;50:808-814. doi: 10.1002/ hep.23082.

[92] Lee YM, Kaplan MM, Vakil N, Arlow FL, Carey WD, Cheney CP, et al. Management of primary sclerosing cholangitis. Am J Gastroenterol 2002; 97:528-534.

[93] Boberg KM, Egeland T, Schrumpf E. Long-term effect of corticosteroid treatment in primary sclerosing cholangitis patients. Scand J Gastroenterol 2003;38:991-995.

[94] Bergasa NV, Mason A, Floreani A, Heathcote J, Swain MG, Jones DE, et al. Primary biliary cirrhosis: report of a focus study group. Hepatology 2004; 40:1013-1020. doi: 10.1002/hep.1840400434.

[95] Talwalkar JA, Souto E, Jorgensen RA, Lindor KD. Natural history of pruritus in primary biliary cirrhosis. Clin Gastroenterol Hepatol 2003;1:297-302. doi: 10.1016/S1542-3565(03)00134-4.

[96] ter Borg PC, van Os E, van den Broek WW, Hansen BE, van Buuren HR. Fluvoxamine for fatigue in primary biliary cirrhosis and primary sclerosing cholangitis: a randomised controlled trial [ISRCTN88246634]. BMC Gastroenterol 2004;4:13. doi: 10.1186/1471-230X-4-13.

[97] Talwalkar JA, Donlinger JJ, Gossard AA, Keach JC, Jorgensen RA, Petz JC, et al. Fluoxetine for the treatment of fatigue in primary biliary cirrhosis: a randomized, double-blind controlled trial. Dig Dis Sci 2006;51:1985-1991. doi: $10.1007 /$ s10620-006-9397-5.

[98] Theal JJ, Toosi MN, Girlan L, Heslegrave RJ, Huet PM, Burak KW, et al. A randomized, controlled crossover trial of ondansetron in patients with primary biliary cirrhosis and fatigue. Hepatology 2005;41:1305-1312. doi: 10.1002/hep.20698.

[99] Prince MI, Mitchison HC, Ashley D, Burke DA, Edwards N, Bramble MG, et al. Oral antioxidant supplementation for fatigue associated with primary biliary cirrhosis: results of a multicentre, randomized, placebo-controlled, crossover trial. Aliment Pharmacol Ther 2003;17:137-143. doi: 10.1046/ j.1365-2036.2003.01398.x.

[100] Jones DE, Newton JL. An open study of modafinil for the treatment of daytime somnolence and fatigue in primary biliary cirrhosis. Aliment Pharmacol Ther 2007;25:471-476. doi: 10.1111/j.1365-2036.2006.03223.x.

[101] Younossi ZM, Boparai N, Price LL, Kiwi ML, McCormick M, Guyatt G. Healthrelated quality of life in chronic liver disease: the impact of type and severity of disease. Am J Gastroenterol 2001;96:2199-2205. doi: 10.1111/j.1572-0241.2001.03956.x.

[102] Bolier $\mathrm{R}$, Oude Elferink RP, Beuers U. Advances in pathogenesis and treatment of pruritus. Clin Liver Dis 2013;17:319-329. doi: 10.1016/ j.cld.2012.11.006.

[103] Jones EA, Bergasa NV. The pruritus of cholestasis: from bile acids to opiate agonists. Hepatology 1990;11:884-887. doi: 10.1002/hep.1840110526.

[104] Beuers U, Kremer AE, Bolier R, Elferink RP. Pruritus in cholestasis: facts and fiction. Hepatology 2014;60:399-407. doi: 10.1002/hep.26909.

[105] Kremer AE, van Dijk R, Leckie P, Schaap FG, Kuiper EM, Mettang $T$, et al. Serum autotaxin is increased in pruritus of cholestasis, but not of other origin, and responds to therapeutic interventions. Hepatology 2012;56: 1391-1400. doi: 10.1002/hep.25748.

[106] Younossi ZM, Kiwi ML, Boparai N, Price LL, Guyatt G. Cholestatic liver diseases and health-related quality of life. Am J Gastroenterol 2000;95: 497-502.
[107] Kaplan MM, Elta GH, Furie B, Sadowski JA, Russell RM. Fat-soluble vitamin nutriture in primary biliary cirrhosis. Gastroenterology 1988;95:787-792.

[108] Jorgensen RA, Lindor KD, Sartin JS, LaRusso NF, Wiesner RH. Serum lipid and fat-soluble vitamin levels in primary sclerosing cholangitis. J Clin Gastroenterol 1995;20:215-219. doi: 10.1097/00004836-19950400000011.

[109] Phillips JR, Angulo P, Petterson T, Lindor KD. Fat-soluble vitamin levels in patients with primary biliary cirrhosis. Am J Gastroenterol 2001;96:27452750. doi: 10.1111/j.1572-0241.2001.04134.x

[110] Kowdley KV. Lipids and lipid-activated vitamins in chronic cholestatic diseases. Clin Liver Dis 1998;2:373-89,x. doi: 10.1016/S10893261(05)70013-1.

[111] Guichelaar MM, Kendall R, Malinchoc M, Hay JE. Bone mineral density before and after OLT: long-term follow-up and predictive factors. Liver Transpl 2006;12:1390-1402. doi: 10.1002/lt.20874.

[112] Leslie WD, Morin SN. Osteoporosis epidemiology 2013: implications for diagnosis, risk assessment, and treatment. Curr Opin Rheumatol 2014;26 440-446. doi: 10.1097/BOR.0000000000000064.

[113] Ruiz-Gaspa S, Martinez-Ferrer A, Guanabens N, Dubreuil M, Peris $P$, Enjuanes $A$, et al. Effects of bilirubin and sera from jaundiced patients on osteoblasts: contribution to the development of osteoporosis in liver diseases. Hepatology 2011;54:2104-2113. doi: 10.1002/hep.24605.

[114] Le Gars L. Bone involvement in patients with chronic cholestasis. Joint Bone Spine 2002;69:373-378. doi: 10.1016/S1297-319X(02)00413-X

[115] Leslie WD, Bernstein CN, Leboff MS, American Gastroenterologica Association Clinical Practice Commitee. AGA technical review on osteoporosis in hepatic disorders. Gastroenterology 2003;125:941-966. doi: 10.1016/S0016-5085(03)01062-X.

[116] Angulo P, Grandison GA, Fong DG, Keach JC, Lindor KD, Bjornsson E, et al. Bone disease in patients with primary sclerosing cholangitis. Gastroenterology 2011;140:180-188. doi: 10.1053/j.gastro.2010.10.014.

[117] Millonig G, Graziadei IW, Eichler D, Pfeiffer KP, Finkenstedt G, Muehllechner $\mathrm{P}$, et al. Alendronate in combination with calcium and vitamin D prevents bone loss after orthotopic liver transplantation: a prospective single-center study. Liver Transpl 2005;11:960-966. doi: 10.1002/It.20466.

[118] Masaki K, Shiomi S, Kuroki T, Tanaka T, Monna T, Ochi H. Longitudinal changes of bone mineral content with age in patients with cirrhosis of the liver. J Gastroenterol 1998;33:236-240. doi: 10.1007/s005350050076.

[119] Iwamoto J, Takada T, Sato Y. Vitamin K nutritional status and undercarboxylated osteocalcin in postmenopausal osteoporotic women treated with bisphosphonates. Asia Pac J Clin Nutr 2014;23:256-262. doi 10.6133/apjcn.2014.23.2.15.

[120] Ruiz-Gaspa S, Guanabens N, Enjuanes A, Peris P, Martinez-Ferrer A, de Osaba MJ, et al. Lithocholic acid downregulates vitamin $D$ effects in human osteoblasts. Eur J Clin Invest 2010;40:25-34. doi: 10.1111/j.13652362.2009.02230.x

[121] Dubreuil M, Ruiz-Gaspa S, Guanabens N, Peris P, Alvarez L, Monegal A, et al. Ursodeoxycholic acid increases differentiation and mineralization and neutralizes the damaging effects of bilirubin on osteoblastic cells. Liver Int 2013;33:1029-1038. doi: 10.1111/liv.12153.

[122] Komatsuda A, Wakui $H$, Ohtani $H$, Masai $R$, Okuyama $S$, Nimura $T$, et al. Tubulointerstitial nephritis and renal tubular acidosis of different types are rare but important complications of primary biliary cirrhosis. Nephrol Dial Transplant 2010;25:3575-3579. doi: 10.1093/ndt/gfq232.

[123] Lino M, Binaut R, Noel LH, Patey N, Rustin P, Daniel L, et al. Tubulointerstitia nephritis and Fanconi syndrome in primary biliary cirrhosis. Am J Kidney Dis 2005;46:e41-e46. doi: 10.1053/j.ajkd.2005.05.021.

[124] Pares A, Rimola A, Bruguera M, Mas E, Rodes J. Renal tubular acidosis in primary biliary cirrhosis. Gastroenterology 1981;80:681-686.

[125] Sun L, Guo W, Yin C, Zhang S, Qu G, Hou Y, et al. Hepcidin deficiency undermines bone load-bearing capacity through inducing iron overload. Gene 2014;543:161-165. doi: 10.1016/j.gene.2014.02.023.

[126] Haider A, Meergans U, Traish A, Saad F, Doros G, Lips P, et al. Progressive improvement of T-scores in men with osteoporosis and subnormal serum testosterone levels upon treatment with testosterone over six years. Int J Endocrinol 2014;2014:496948. doi: 10.1155/2014/496948.

[127] Zheng J, Mao X, Ling J, He Q, Quan J. Low serum levels of zinc, copper, and iron as risk factors for osteoporosis: a meta-analysis. Biol Trace Elem Res 2014;160:15-23. doi: 10.1007/s12011-014-0031-7.

[128] Ardawi MS, Akhbar DH, Alshaikh A, Ahmed MM, Qari MH, Rouzi AA, et al. Increased serum sclerostin and decreased serum IGF-1 are associated with vertebral fractures among postmenopausal women with type-2 diabetes. Bone 2013;56:355-362. doi: 10.1016/j.bone.2013.06.029.

[129] Guanabens N, Pares A, Ros I, Caballeria L, Pons F, Vidal S, et al. Severity of cholestasis and advanced histological stage but not menopausal status are the major risk factors for osteoporosis in primary biliary cirrhosis. J Hepatol 2005;42:573-577. doi: 10.1016/j.jhep.2004.11.035

[130] Guanabens N, Cerda D, Monegal A, Pons F, Caballeria L, Peris P, et al. Low bone mass and severity of cholestasis affect fracture risk in patients with 
primary biliary cirrhosis. Gastroenterology 2010;138:2348-2356. doi: 10.1053/j.gastro.2010.02.016.

[131] Mounach A, Ouzzif Z, Wariaghli G, Achemlal L, Benbaghdadi I, Aouragh A, et al. Primary biliary cirrhosis and osteoporosis: a case-control study. J Bone Miner Metab 2008;26:379-384. doi: 10.1007/s00774-007-0833-1.

[132] Solaymani-Dodaran M, Card TR, Aithal GP, West J. Fracture risk in people with primary biliary cirrhosis: a population-based cohort study. Gastroenterology 2006;131:1752-1757. doi: 10.1053/j.gastro.2006.09.012.

[133] Menon KV, Angulo P, Weston S, Dickson ER, Lindor KD. Bone disease in primary biliary cirrhosis: independent indicators and rate of progression. J Hepatol 2001;35:316-323. doi: 10.1016/S0168-8278(01)00144-1.

[134] Benetti A, Crosignani A, Varenna M, Giussani CS, Allocca M, Zuin M, et al. Primary biliary cirrhosis is not an additional risk factor for bone loss in women receiving regular calcium and vitamin D supplementation: a controlled longitudinal study. J Clin Gastroenterol 2008;42:306-311. doi: 10.1097/01. mcg.0000248017.31386.39.

[135] Rudic JS, Giljaca V, Krstic MN, Bjelakovic G, Gluud C. Bisphosphonates for osteoporosis in primary biliary cirrhosis. Cochrane Database Syst Rev 2011;(12):CD009144. doi:CD009144.

[136] Bernstein CN, Seeger LL, Sayre JW, Anton PA, Artinian L, Shanahan F. Decreased bone density in inflammatory bowel disease is related to corticosteroid use and not disease diagnosis. J Bone Miner Res 1995;10: 250-256. doi: 10.1002/jbmr.5650100211.

[137] Eastell R, Dickson ER, Hodgson SF, Wiesner RH, Porayko MK, Wahner HW, et al. Rates of vertebral bone loss before and after liver transplantation in women with primary biliary cirrhosis. Hepatology $1991 ; 14: 296-300$. doi: $10.1002 /$ hep. 1840140215

[138] Hodgson SF, Dickson ER, Eastell R, Eriksen EF, Bryant SC, Riggs BL. Rates of cancellous bone remodeling and turnover in osteopenia associated with primary biliary cirrhosis. Bone 1993;14:819-827. doi: 10.1016/87563282(93)90310-7.

[139] Anonymous Assessment of fracture risk and its application to screening for postmenopausal osteoporosis. Report of a WHO Study Group. World Health Organ Tech Rep Ser 1994;843:1-129

[140] Angulo P, Therneau TM, Jorgensen A, DeSotel CK, Egan KS, Dickson ER, et al. Bone disease in patients with primary sclerosing cholangitis: prevalence, severity and prediction of progression. J Hepatol 1998;29: 729-735. doi: 10.1016/S0168-8278(98)80253-5.

[141] Lindor KD, Janes CH, Crippin JS, Jorgensen RA, Dickson ER. Bone disease in primary biliary cirrhosis: does ursodeoxycholic acid make a difference? Hepatology 1995 21:389-392.

[142] Crawford BA, Kam C, Pavlovic J, Byth K, Handelsman DJ, Angus PW, et al. Zoledronic acid prevents bone loss after liver transplantation: a randomized, double-blind, placebo-controlled trial. Ann Intern Med 2006;144: 239-248. doi: 10.7326/0003-4819-144-4-200602210-00005.

[143] Hay JE, Malinchoc M, Dickson ER. A controlled trial of calcitonin therapy for the prevention of post-liver transplantation atraumatic fractures in patients with primary biliary cirrhosis and primary sclerosing cholangitis. J Hepatol 2001;34:292-298. doi: 10.1016/S0168-8278(00)00093-3.

[144] Floreani A, Zappala F, Fries W, Naccarato R, Plebani M, D'Angelo A, et al. A 3year pilot study with 1,25-dihydroxyvitamin $D$, calcium, and calcitonin for severe osteodystrophy in primary biliary cirrhosis. J Clin Gastroenterol 1997;24:239-244. doi: 10.1097/00004836-199706000-00012.

[145] Zein CO, Jorgensen RA, Clarke B, Wenger DE, Keach JC, Angulo P, et al. Alendronate improves bone mineral density in primary biliary cirrhosis: a randomized placebo-controlled trial. Hepatology 2005;42:762-771. doi: 10.1002/hep.20866

[146] Rudic JS, Poropat G, Krstic MN, Bjelakovic G, Gluud C. Hormone replacement for osteoporosis in women with primary biliary cirrhosis. Cochrane Database Syst Rev 2011;(12):CD009146. doi: 10.1002/14651858.CD009146.pub2.

[147] Menon KV, Angulo P, Boe GM, Lindor KD. Safety and efficacy of estrogen therapy in preventing bone loss in primary biliary cirrhosis. Am J Gastroenterol 2003;98:889-892. doi: 10.1111/j.15720241.2003.07341.x.

[148] Olsson R, Mattsson LA, Obrant K, Mellstrom D. Estrogen-progestogen therapy for low bone mineral density in primary biliary cirrhosis. Liver 1999; 19:188-192. doi: 10.1111/j.1478-3231.1999.tb00034.x.

[149] Crippin JS, Jorgensen RA, Dickson ER, Lindor KD. Hepatic osteodystrophy in primary biliary cirrhosis: effects of medical treatment. Am J Gastroenterol $1994 ; 89: 47-50$

[150] Boone RH, Cheung AM, Girlan LM, Heathcote EJ. Osteoporosis in primary biliary cirrhosis: a randomized trial of the efficacy and feasibility of estrogen/progestin. Dig Dis Sci 2006;51:1103-1112. doi: 10.1007/ s10620-006-8015-x.

[151] Van Erpecum KJ, Van Berge Henegouwen GP, Verschoor L, Stoelwinder B, Willekens FL. Different hepatobiliary effects of oral and transderma estradiol in postmenopausal women. Gastroenterology 1991;100:482488.

[152] Ko DT, Wijeysundera HC, Udell JA, Vaccarino V, Austin PC, Guo H, et al. Traditional cardiovascular risk factors and the presence of obstructive coronary artery disease in men and women. Can J Cardiol 2014;30:820826. doi: 10.1016/j.cjca.2014.04.032.

[153] Jahn CE, Schaefer EJ, Taam LA, Hoofnagle JH, Lindgren FT, Albers J], et al. Lipoprotein abnormalities in primary biliary cirrhosis. Association with hepatic lipase inhibition as well as altered cholesterol esterification. Gastroenterology 1985;89:1266-1278.

[154] Longo M, Crosignani A, Battezzati PM, Squarcia Giussani C, Invernizzi $P_{\text {, }}$ Zuin $\mathrm{M}$, et al. Hyperlipidaemic state and cardiovascular risk in primary biliary cirrhosis. Gut 2002;51:265-269. doi: 10.1136/gut.51.2.265.

[155] Cash WJ, O'Neill S, O'Donnell ME, McCance DR, Young IS, McEneny ], et al. Randomized controlled trial assessing the effect of simvastatin in primary biliary cirrhosis. Liver Int 2013;33:1166-1174. doi: 10.1111/liv.12191.

[156] Miller JP. Dyslipoproteinaemia of liver disease. Baillieres Clin Endocrinol Metab 1990;4:807-832. doi: 10.1016/S0950-351X(05)80080-1.

[157] Sorokin A, Brown JL, Thompson PD. Primary biliary cirrhosis, hyperlipidemia, and atherosclerotic risk: a systematic review. Atherosclerosis 2007; 194:293-299. doi: 10.1016/j.atherosclerosis.2006.11.036.

[158] Walli A K, Seidel D. Role of lipoprotein-X in the pathogenesis of cholestatic hypercholesterolemia. Uptake of lipoprotein-X and its effect on 3-hydroxy3-methylglutaryl coenzyme A reductase and chylomicron remnant removal in human fibroblasts, lymphocytes, and in the rat. J Clin Invest $1984 ; 74$ 867-879. doi: 10.1172/JCI111504.

[159] Chang PY, Lu SC, Su TC, Chou SF, Huang WH, Morrisett JD, et al. Lipoprotein-X reduces LDL atherogenicity in primary biliary cirrhosis by preventing LDL oxidation. J Lipid Res 2004;45:2116-2122. doi: 10.1194/ jlr.M400229-JLR200.

[160] Edwards CM, Otal MP, Stacpoole PW. Lipoprotein-X fails to inhibit hydroxymethylglutaryl coenzyme A reductase in HepG2 cells. Metabolism: Clinical and Experimental 1993;42:807-813. doi: 10.1016/00260495(93)90051-O.

[161] Crippin JS, Lindor KD, Jorgensen R, Kottke BA, Harrison JM, Murtaugh PA, et al. Hypercholesterolemia and atherosclerosis in primary biliary cirrhosis: what is the risk? Hepatology 1992;15:858-862. doi: 10.1002/ hep. 1840150518 .

[162] Van Dam GM, Gips CH. Primary biliary cirrhosis in The Netherlands. An analysis of associated diseases, cardiovascular risk, and malignancies on the basis of mortality figures. Scand J Gastroenterol 1997;32:77-83.

[163] Sinakos E, Abbas G, Jorgensen RA, Lindor KD. Serum lipids in primary sclerosing cholangitis. Dig Liver Dis 2012;44:44-48. doi: 10.1016/ j.dld.2011.07.020.

[164] Ludvigsson JF, Bergquist A, Montgomery SM, Bahmanyar S. Risk of diabetes and cardiovascular disease in patients with primary sclerosing cholangitis. J Hepatol 2014;60:802-808. doi: 10.1016/j.jhep.2013.11.017.

[165] Ahrens EH Jr, Kunkel HG. The relationship between serum lipids and skin xanthomata in 18 patients with primary biliary cirrhosis. J Clin Invest 1949; 28:1565-1574. doi: 10.1172/JCI102222.

[166] Ambinder EP, Cohen LB, Wolke AM, Field SP, Adelsberg B, Schaffner F, et al. The clinical effectiveness and safety of chronic plasmapheresis in patients with primary biliary cirrhosis. J Clin Apheresis 1985;2:219-223. doi: 10.1002/jca.2920020303.

[167] Stone NJ, Robinson JG, Lichtenstein AH, Bairey Merz CN, Blum CB, Eckel RH, et al. 2013 ACC/AHA Guideline on the Treatment of Blood Cholesterol to Reduce Atherosclerotic Cardiovascular Risk in Adults: A Report of the American College of Cardiology/American Heart Association Task Force on Practice Guidelines. J Am Coll Cardiol 2014;63:2889-2934. doi: 10.1016/ j.jacc.2013.11.002.

[168] Pencina MJ, Navar-Boggan AM, D’Agostino RB Sr, Williams K, Neely B, Sniderman $A D$, et al. Application of new cholesterol guidelines to a population-based sample. N Engl J Med 2014;370:1422-1431. doi: 10.1056/NEJMoa1315665.

[169] Kurihara T, Akimoto M, Abe K, Ishiguro H, Niimi A, Maeda A, et al. Experimental use of pravastatin in patients with primary biliary cirrhosis associated with hypercholesterolemia. Clin Ther 1993;15:890-898.

[170] Ritzel U, Leonhardt U, Näther M, Schäfer G, Armstrong VW, Ramadori G. Simvastatin in primary biliary cirrhosis: effects on serum lipids and distinct disease markers. J Hepatol 2002; 36:454-458. doi: 10.1016/S0168 8278(02)00006-5.

[171] Del Puppo M, Galli Kienle M, Crosignani A, Petroni ML, Amati B, Zuin M, et al. Cholesterol metabolism in primary biliary cirrhosis during simvastatin and UDCA administration. J Lipid Res 2001;42:437-441.

[172] Balan V, Dickson ER, Jorgensen RA, Lindor KD. Effect of ursodeoxycholic acid on serum lipids of patients with primary biliary cirrhosis. Mayo Clin Proc 1994;69:923-929. doi: 10.1016/S0025-6196(12)61815-1.

[173] Gandelman G, Aronow WS, Weiss MB. Resolving hyperlipidemia after liver transplantation in a patient with primary sclerosing cholangitis. Am J Ther 2006;13:171-174.

[174] Hay JE. Liver disease in pregnancy. Hepatology 2008;47:1067-1076. doi: 10.1002/hep. 22130 
[175] Lata I. Hepatobiliary diseases during pregnancy and their management: an update. Int J Crit Illn Inj Sci 2013;3:175-182. doi: 10.4103/22295151.119196.

[176] Than NN, Neuberger J. Liver abnormalities in pregnancy. Best Pract Res Clin Gastroenterol 2013;27:565-575. doi: 10.1016/j.bpg.2013.06.015.

[177] Everson GT. Liver problems in pregnancy: distinguishing normal from abnormal hepatic changes. Medscape Womens Health 1998;3:3.

[178] Trivedi P J, Kumagi T, Al-Harthy N, Coltescu C, Ward S, Cheung A, et al. Good maternal and fetal outcomes for pregnant women with primary biliary cirrhosis. Clinical Gastroenterology and Hepatology 2014;12:11791185.e1. doi: 10.1016/j.cgh.2013.11.030.

[179] Efe C, Kahramanoglu-Aksoy E, Yilmaz B, Ozseker B, Takci S, Roach EC, et al. Pregnancy in women with primary biliary cirrhosis. Autoimmun Rev 2014;13:931-935. doi: 10.1016/j.autrev.2014.05.008.

[180] Floreani A, Infantolino C, Franceschet I, Tene IM, Cazzagon N, Buja A, et al. Pregnancy and primary biliary cirrhosis: a case-control study. Clin Rev Allergy Immunol 2014.

[181] Cresswell JA, Ronsmans C, Calvert C, Filippi V. Prevalence of placenta praevia by world region: a systematic review and meta-analysis. Trop Med Int Health 2013;18:712-724. doi: 10.1111/tmi.12100.

[182] Janczewska I, Olsson R, Hultcrantz R, Broome U. Pregnancy in patients with primary sclerosing cholangitis. Liver 1996;16:326-330. doi: 10.1111/ j.1600-0676.1996.tb00754.x.

[183] Wellge BE, Sterneck M, Teufel A, Rust C, Franke A, Schreiber S, et al. Pregnancy in primary sclerosing cholangitis. Gut $2011 ; 60: 1117-1121$. doi: 10.1136/gut.2010.228924.

[184] Ludvigsson JF, Bergquist A, Ajne G, Kane S, Ekbom A, Stephansson O. A population-based cohort study of pregnancy outcomes among women with primary sclerosing cholangitis. Clin Gastroenterol Hepatol 2014;12:95100. doi: $10.1016 /$ j.cgh.2013.07.011.

[185] Glantz A, Marschall HU, Mattsson LA. Intrahepatic cholestasis of pregnancy: relationships between bile acid levels and fetal complication rates. Hepatology 2004;40:467-474. doi: 10.1002/hep.20336.

[186] Brites D, Rodrigues CM. Elevated levels of bile acids in colostrum of patients with cholestasis of pregnancy are decreased following ursodeoxycholic acid therapy. J Hepatol 1998;29:743-751. doi: 10.1016/S0168-8278(98)80255-9.

[187] Meng LJ, Reyes H, Axelson M, Palma J, Hernandez I, Ribalta J, et al. Progesterone metabolites and bile acids in serum of patients with intrahepatic cholestasis of pregnancy: effect of ursodeoxycholic acid therapy. Hepatology 1997;26:1573-1579. doi: 10.1002/hep.510260627.
[188] Poupon R, Chretien Y, Chazouilleres O, Poupon RE. Pregnancy in women with ursodeoxycholic acid-treated primary biliary cirrhosis. J Hepatol 2005; 42:418-419. doi: 10.1016/j.jhep.2004.08.029.

[189] Boregowda G, Shehata HA. Gastrointestinal and liver disease in pregnancy. Best Pract Res Clin Obstet Gynaecol 2013;27:835-853. doi: 10.1016/ j.bpobgyn.2013.07.006.

[190] Gurung V, Middleton P, Milan SJ, Hague W, Thornton JG. Interventions for treating cholestasis in pregnancy. Cochrane Database Syst Rev 2013;6: CD000493. doi: 10.1002/14651858.CD000493.pub2.

[191] Lucey MR, Terrault N, Ojo L, Hay JE, Neuberger J, Blumberg E, et al. Longterm management of the successful adult liver transplant: 2012 practice guideline by the American Association for the Study of Liver Diseases and the American Society of Transplantation. Liver Transpl 2013;19:3-26. doi: $10.1002 / \mathrm{lt} .23566$.

[192] Fevery J, Henckaerts L, Van Oirbeek R, Vermeire S, Rutgeerts P, Nevens F, et al. Malignancies and mortality in 200 patients with primary sclerosing cholangitis: a long-term single-centre study. Liver Int 2012;32:214-222. doi: $10.1111 / \mathrm{j} .1478-3231.2011 .02575 . x$.

[193] Bruix J, Sherman M, American Association for the Study of Liver Diseases. Management of hepatocellular carcinoma: an update. Hepatology 2011;53: 1020-1022. doi: 10.1002/hep.24199.

[194] Garcia-Tsao G, Sanyal AJ, Grace ND, Carey W, Practice Guidelines Committee of the American Association for the Study of Liver Diseases, Practice Parameters Committee of the American College of Gastroenterology. Prevention and management of gastroesophageal varices and variceal hemorrhage in cirrhosis. Hepatology 2007;46:922938. doi: 10.1002/hep.21907.

[195] The Johns Hopkins School of Medicine Department of Gynecology. The Johns Hopkins Manual of Gynecology and Obstetrics: Lippincott Williams \& Wilkins.

[196] Ambros-Rudolph CM, Mullegger RR, Vaughan-Jones SA, Kerl H, Black MM. The specific dermatoses of pregnancy revisited and reclassified: results of a retrospective two-center study on 505 pregnant patients. J Am Acad Dermatol 2006;54:395-404. doi: 10.1016/j.jaad.2005.12.012.

[197] Vaughan Jones SA, Hern S, Nelson-Piercy C, Seed PT, Black MM. A prospective study of 200 women with dermatoses of pregnancy correlating clinical findings with hormonal and immunopathological profiles. $\mathrm{Br}$ J Dermatol 1999;141:71-81. doi: 10.1046/j.1365-2133.1999.0 2923.x. 